\title{
DECLINACIÓN Y DESTINO DE LAS EXPORTACIONES DE PETRÓLEO CRUDO MEXICANO
}

\author{
DECLINE AND RECIPIENTS \\ OF MEXICAN CRUDE OIL EXPORTS
}

DIMINUTION ET DESTINATIONS

DES EXPORTATIONS

DE PÉTROLE BRUT MEXICAIN

\author{
Adrián Lajous \\ Universidad de Columbia \\ alajous@petrometrica.com
}

\begin{abstract}
Resumen: La primera parte del artículo traza la declinación de las exportaciones mexicanas en el contexto de la creciente producción en Estados Unidos y Canadá; analiza la evolución del mercado de crudo pesado en la costa estadounidense del Golfo; trata las perspectivas de la producción de crudo pesado mexicano. La segunda se concentra en la dirección geográfica de las exportaciones; examina sus precios, en particular del crudo pesado; explora otros aspectos de la política comercial de PEMEx; subraya el oneroso costo que ha tenido la diversificación de las exportaciones de crudo a Europa y Asia. El artículo concluye que la actual estrategia de exportación de PEMEX se ha agotado y recomienda que la empresa estatal la rediseñe para hacer frente a nuevas circunstancias del mercado petrolero en México y en el exterior.
\end{abstract}

Palabras clave: Exportaciones de crudo; crudo pesado; declinación; diversificación; agotamiento estratégico.

Aвstract: The first part of this article examines the decline of Mexican exports in the context of growing production in the United States and Canada, analyzes the evolution of the market for heavy crude on the U.S. Gulf coast, and looks at the prospects for production of Mexican heavy crude. The second part focuses on the geographic direction of exports, examines prices (especially for heavy crude), explores other aspects of PEMEx's commercial policies, and underlines the onerous cost of the diversification of crude exports to Europe and 
Asia. The article concludes that PEMEX's current export strategy is out of date and recommends that the state-owned company restructure it in order to address the new circumstances of the oil market both in Mexico and abroad.

Keywords: Crude exports; heavy crude; decline; diversification; strategic exhaustion.

\section{Traducción de Gonzalo Celorio Morayta}

RÉSumÉ: La première partie de l'article décrit la diminution des exportations de pétrole brut mexicain, face à la production croissante aux États-Unis et au Canada; elle trace l'évolution du marché du brut lourd le long de la côte du Golfe des États-Unis; elle traite aussi des perspectives de la production de brut lourd au Mexique. La seconde partie présente la géographie des exportations; elle examine les prix, notamment ceux du brut lourd; elle aborde d'autres aspects de la politique commerciale de PEMEx et elle souligne le coût élevé du réacheminement des exportations de brut vers l'Europe et l'Asie. L'article tire la conclusion que la stratégie d'exportation actuelle de PEMEX est épuisée, donc cette entreprise publique devrait la modifier pour mieux s'attaquer aux nouvelles conditions du marché pétrolier mexicain et mondial.

Mots clefs: Exportations de brut, brut lourd, diminution, diversification, épuisement d'une stratégie.

Traducción de Bernardo Mabire

Fecha de recepción: octubre de 2017

Fecha de aceptación: octubre de 2018 
$\mathrm{E}$ balance del petróleo crudo de México presenta síntomas cada vez más preocupantes." Unos cuantos datos estilizados revelan tendencias inequívocas. La producción cruzó, a la baja, el umbral de los 2 millones de barriles diarios (mmbd) en julio de 2017 y aún no toca fondo. En 2004, se produjeron 3.4 mmbd y las refinerías de PEMEX procesaron ese año un total de $1.3 \mathrm{mmbd}$. Esta última cifra descendió a 767 mil barriles diarios (mbd) en 2017. Así, la exportación neta de hidrocarburos líquidos -las ventas exteriores de crudo y de productos petrolíferos menos las importaciones de estos últimos- se precipitó a 409 mbd en el primer semestre de 2018, es decir una baja del $77 \%$ respecto al $2004 .{ }^{1}$ Por entonces, México pasó de ser el quinto país productor de petróleo en ese año a ocupar el onceavo lugar en $2016 .^{2}$

Esta declinación de largo plazo refleja la madurez del acervo de reservas petroleras, una administración deficiente de yacimientos, prácticas ineficientes de producción, la subinversión secular en actividades de exploración y desarrollo y una asignación poco eficiente de la inversión. En fechas recientes, particularmente a partir del colapso de los precios del petróleo, PEMEx redujo sustancialmente sus inversiones en exploración y producción. En 2014, invirtió 277 mil millones de pesos y el gasto de inversión realizado en 2017 fue de 113 mil millones, es decir una reducción del 59\%. ${ }^{3}$ En 2018,

* El autor recibió comentarios y sugerencias a una versión preliminar de este artículo de colegas y amigos. Entre ellos, desea reconocer en particular los hechos por Rosanety Barrios, Juan Carlos Boué, Pedro Haas, Bernardo de la Garza, Felipe Luna, Guillermo Ruiz y Ricardo Samaniego, así como por los dictaminadores anónimos. Desde luego, las opiniones y los errores son de su exclusiva responsabilidad.

${ }^{1}$ Pemex, "Base de Datos Institucional", en https://www.ebdi.pemex. com.

2 вр, Statistical Review of World Energy, junio de 2018, en https://www. bp.com/content/dam/bp/en/corporate/pdf/energy-economics/statistical-review/bp-stats-review-2018-full-report.pdf

${ }^{3}$ U.S. Securities and Exchange Commission, "Petróleos Mexicanos, Annual Report (20F)", 2016 y 2017, pp. 21 y 22, respectivamente, en https://www.pemex.com/ri/reguladores/Paginas/informacion_sec. 
el presupuesto de inversión se mantuvo constante en términos monetarios respecto al ejercicio del año anterior, lo que no es un buen augurio para PEMEx. El efecto compuesto de tendencias estructurales de largo plazo y de factores propios del ciclo industrial de corto plazo ha sido devastador. Dada la debilidad financiera de PEMEX, una profunda crisis de cuatro años de duración hizo que la perforación de pozos cayera vertiginosamente, se difirieran múltiples proyectos de inversión y se contrajera la compra de materiales, equipos y servicios petroleros de manera significativa. En este periodo, el impacto sobre las actividades de desarrollo y de producción ha sido severo y todo indica que la producción de petróleo y gas natural continuará a la baja en los próximos 3 ó 4 años. Los resultados de la inversión privada en la industria petrolera mexicana difícilmente lograrán compensar la contracción previsible en PEMEX.

La declinación y el destino de las exportaciones a que alude el título de este artículo se refieren a la evolución y tendencia a mediano plazo de este flujo y a la dirección geográfica del mismo. La primera, que es el determinante, no parece tener remedio en dicho marco temporal. El segundo puede corregirse, aunque sólo sea parcialmente, mediante mecanismos de mercado. Se requerirían una inversión sustancial de Pemex y de particulares, una serie de descubrimientos extraordinarios y una fuerte restitución de reservas para restablecer el nivel de las exportaciones de petróleo crudo alcanzado en 2004. Una meta más modesta, como pudiera ser alcanzar el monto realizado en 2016, requiere también grandes inversiones y probar reservas significativamente mayores que las actuales. La exitosa gestión de las refinerías mexicanas tendría como resultado reducir las exportaciones de crudo, así como las importaciones de productos petrolíferos, lo que haría aún más distante el logro de dicha meta. Así, todo apunta a que la exportación de crudo no se recuperará de

aspx. El presupuesto de 2018 fue presentado al Consejo de administración de PEMEx el 5 de marzo de 2018. 
manera significativa antes de 2025, a causa de la declinación que se ha observado, el ritmo de agotamiento de las reservas probadas de petróleo crudo y el incremento de la demanda interna.

La caída de las exportaciones de crudo ha sido determinada por las tendencias descritas de la producción, moderada parcialmente por la reducción del volumen de petróleo crudo procesado en refinerías mexicanas. El menor monto exportado a Estado Unidos ha reflejado estos mismos factores, magnificados por la política de diversificación de las exportaciones instrumentada por PEMEx. En la etapa actual de la producción, la declinación y la diversificación del destino de las exportaciones obedecen a factores muy diferentes. Se trata de procesos que no están funcionalmente vinculados. La diversificación del destino geográfico de las exportaciones de crudo es una estrategia que pretende administrar riesgos de mercado y puede también perseguir otros objetivos comerciales y de carácter político. El régimen de precios FOB ('libre a bordo', en inglés) del crudo por regiones de destino permite medir los costos de la diversificación, los cuales se deducen de los beneficios potenciales que pueden obtenerse de ella.

Uno de los dos temas centrales de este trabajo es la diversificación geográfica de las exportaciones de petróleo crudo mexicano, que se aceleró a partir de 2014, en el contexto de una importante reducción del excedente exportable. En los últimos cuatro años, Petróleos Mexicanos Internacional (PMI) reorientó con vigor la dirección de sus exportaciones de crudo de Estados Unidos a Europa y Asia. En 2016, sus ventas de crudo al Vecino del Norte descendieron al $49 \%$ del total, cifra nunca antes registrada desde que México reinició sus exportaciones a mediados de los años setenta. Todavía en 2012 el $76 \%$ de las exportaciones tenía como destino tal país. ${ }^{4}$ Sin embargo, esta diversificación no se sustenta en los precios obtenidos en otros mercados y plantea un enigma difícil de

${ }^{4}$ Ibidem, p. 88. 
resolver. Una mejor comprensión de la dinámica de la producción, el transporte y los precios, así como la evolución de los balances de crudo de Norteamérica, son necesarios para evaluar el comportamiento de las exportaciones mexicanas y su diversificación. Su análisis revela también problemas más amplios y profundos asociados al agotamiento de la actual estrategia comercial de PMI.

Este artículo se estructura en tres partes. La primera trata de la evolución reciente y los prospectos a mediano plazo de las exportaciones de petróleo crudo mexicano en el contexto de la creciente producción de Norteamérica y la contracción de las exportaciones de crudo pesado del resto del Continente a Estados Unidos. La segunda analiza las posibles determinantes de la diversificación observada. La tercera ofrece un resumen de las principales conclusiones y de algunas recomendaciones derivadas del presente trabajo desde una perspectiva mexicana.

La primera sección de la primera parte traza la declinación de las exportaciones de petróleo mexicano y de la producción. Una segunda sección analiza la evolución del mercado de petróleo crudo pesado de la costa estadounidense del Golfo -el más grande del mundo-, al que se dirigen preponderantemente las exportaciones de Venezuela, México y Canadá, países que se especializan en la producción de este tipo de crudos. En la tercera, se tratan las perspectivas de la producción de crudo pesado mexicano y se identifican algunos proyectos que podrían aportar producción adicional a mediano y más largo plazo. En la segunda parte, se examinan los precios de exportación del crudo mexicano, así como los mecanismos que los determinan, en particular los de crudo pesado. Más adelante se exploran otros factores que condicionan los riesgos y los costos de una estrategia comercial a la deriva. Resaltan entre éstas que la diversificación emprendida por la anterior administración de PEMEx resultó costosa, provocó daños que fueron autoinfligidos y no se consideraron posibles cambios en el mercado petrolero, que debilitan la posición competitiva de PEMEX. Para concluir, PMI está ahora 
obligado a precisar mejor sus objetivos, diseñar nuevas estrategias, robustecer sus instrumentos comerciales y redefinir su alcance institucional para hacer frente a nuevas circunstancias del mercado petrolero en México y en el exterior.

\section{Producción y eXPORTAGiones EN NorTeAmérica}

La producción total de petróleo crudo en México ha disminuido en los últimos 13 años y su nivel en 2017 fue un 42\% más bajo que el máximo alcanzado en 2004. Las cuatro regiones petroleras en las que se divide el país vieron disminuida su producción durante este periodo. Asimismo, de entre los 12 activos en que se agrupan los campos productores de México - uno de los cuales, el Litoral de Tabasco, inició su propia declinación recientemente-, es posible que el complejo Ku-Maloob-Zaap (KMZ) haya alcanzado su nivel máximo de producción; en la cuenca de Chicontepec sólo se ha extraído una baja proporción de sus reservas; la cuenca de Veracruz produce pequeños volúmenes de crudo y ocho activos más se encuentran en una fase avanzada de declinación. Las esperanzas de obtener producción de nuevos campos están puestas principalmente en aguas someras de las cuencas del Sureste, aguas profundas y ultraprofundas del Golfo, a más de yacimientos no convencionales del norte del país y en Chicontepec. Gran parte de esa producción provendrá de campos que aún no han sido descubiertos, la cual servirá para compensar la declinación adicional de campos productores y revertir con el tiempo la tendencia a la baja.

El perfil de la producción petrolera de México responde al ciclo vital de sus yacimientos, sobre todo al de sus campos supergigantes y gigantes. Típicamente, la producción de un campo petrolero avanza en un inicio por una senda expansiva según se incorporan nuevos pozos hasta alcanzar una pla- 
taforma en la que tiende a estabilizarse, cuando nuevos pozos compensan la declinación de otros más antiguos. Alcanzada la producción máxima, comienza la declinación. De manera convencional, ésta puede separarse en tres fases. Primero, cuando la producción desciende al $50 \%$ del nivel pico, después al $25 \%$ y finalmente se agota. ${ }^{5}$ México está cerca de terminar la primera fase de su declinación. En el primer semestre de 2018, la producción de petróleo obtenida equivalió a menos del $55 \%$ del nivel máximo alcanzado en diciembre de $2003{ }^{6}$

Es interesante comparar el perfil de la producción de México con el de otras provincias petroleras, como el North Slope de Alaska y los sectores británico y noruego del Mar del Norte, cuyo descubrimiento y desarrollo son contemporáneos al de las cuencas del sureste de México. El campo Prudhoe en Alaska fue descubierto en 1967. El North Slope alcanzó su producción máxima en 1988 y ha disminuido $76 \%$ hasta el 2017. ${ }^{7}$ Con el campo Ekofisk, descubierto en 1969, se inició la producción de petróleo crudo del sector noruego del Mar del Norte. Éste alcanzó su pico en 1996, año a partir del cual la producción disminuyó $51 \%$. Sin embargo, la producción total de hidrocarburos de Noruega ha de estabilizarse entre 2017 y 2020, cuando volverá a crecer a un ritmo moderado por las aportaciones de campos en el Mar Noruego y en el de Barents, así como por una mayor producción de gas natural. ${ }^{8}$ En 1970, se descubrió el campo Forties en aguas del Reino Unido, sector del Mar del Norte que alcanzó su producción pico en 2001 y ha disminuido $49 \% .{ }^{9}$ En las cuen-

${ }^{5}$ International Energy Agency, World Energy Outlook, París, oEcD/IEA, 2008, cap. 10.

${ }^{6}$ Pemex, "Base de Datos Institucional".

${ }^{7}$ EIA, "Crude Oil Production", en https://www.eia.gov/dnav/pet/ pet_crd_crpdn_adc_mbbl_m.htm.

${ }^{8}$ Norwegian Ministry of Petroleum and Energy, "Production", en https://www.norskpetroleum.no/en/facts/production/.

${ }^{9}$ UK Government, "Crude Oil and Petroleum: Production, Imports and Exports, 1890 to 2017", en https://www.gov.uk/government/statisti- 
cas del Sureste, en 1972, se perforó el campo Cactus y mar adentro el pozo Chac-1, en 1976, y el Akal-1, en 1977, lo cual permitió descubrir el campo supergigante más grande de México. La producción total de estas cuencas alcanzó su nivel máximo en 2004 y disminuyó un 35\% hasta el 2017.

El acervo de reservas probadas de México es particularmente maduro y su envejecimiento continúa avanzando. Hasta el 31 de diciembre de 2017 , el $86 \%$ de las reservas probadas originales ya se habían extraído. ${ }^{10}$ En 2016, más del $90 \%$ de los campos productores del país podían clasificarse como maduros -en los que más del $50 \%$ de las reservas probadas y probables (2P) originales ya se había producido. Al considerar los campos mar adentro, de donde proviene la mayor parte de la producción del país, 44 de ellos son maduros y contribuyeron al final de dicho año con el $69 \%$ de las reservas marinas $2 \mathrm{P},{ }^{11}$ lo cual significa que la posibilidad de detener la declinación y revertirla sólo puede lograrse mediante nuevos descubrimientos y mayores factores de recuperación de reservas, objetivos éstos de mediano y, sobre todo, largo plazo.

En los últimos trece años la tendencia dominante de las exportaciones de crudo mexicano ha sido su declinación, determinada a su vez por una baja sostenida de la producción. En 2017, PMI exportó $1.2 \mathrm{mmbd}$, volumen muy inferior a los 1.9 mmbd alcanzados en 2004, una caída acumulada del $37 \%$.

cal-data-sets / crude-oil-and-petroleum-production-imports-and-exports1890-to-2011.

10 CNH, "Reservas de hidrocarburos", en https://portal.cnih.cnh. gob.mx/estadisticas.php. Las reservas son aquellas cantidades que se prevé serán recuperadas comercialmente de acumulaciones conocidas a una fecha dada. Las reservas $1 \mathrm{P}$ son las reservas probadas, las 2P, la suma de las reservas probadas, más las probables, y las 3P, la suma de las probadas, probables y posibles. Las primeras tienen una probabilidad de al menos $90 \%$ de ser recuperadas, las segundas, una de al menos $50 \%$ y, en el caso de las terceras, la probabilidad es al menos de $10 \%$.

11 G. Franco Hernández, "Opportunities in Mexican Mature Fields", OE Digital, 1 de diciembre de 2017, en https://www.oedigital.com/drilling/rigs/item/16850-opportunities-in-mexican-mature-fields, y CNH, "Reservas de hidrocarburos". 
La reducción habría sido aún mayor, si no se hubiese registrado una baja en el nivel de proceso de las refinerías mexicanas y el consiguiente aumento de las importaciones de productos petrolíferos. Conviene subrayar que la totalidad de la caída de las exportaciones es atribuible al crudo pesado, pues en ese mismo periodo hubo un ligero incremento de las correspondientes a crudo ligero y extraligero. La baja registrada en 2017 no es el resultado de la "declinación natural administrada” de la producción a la que se refirió la Secretaría de Energía (SENER), como parte de la supuesta colaboración de México con la opep, de una reducción voluntaria de las exportaciones de petróleo crudo de hasta $100 \mathrm{mbd}^{12}$

En la gráfica 1, puede observarse la caída sostenida de la producción de petróleo crudo pesado. La brecha entre la producción y la exportación tendió a estrecharse a causa

\section{GRÁFICA 1}

Producción de petróleo crudo pesado

entre 2004 y agosto de 2018

(millones de barriles diarios)

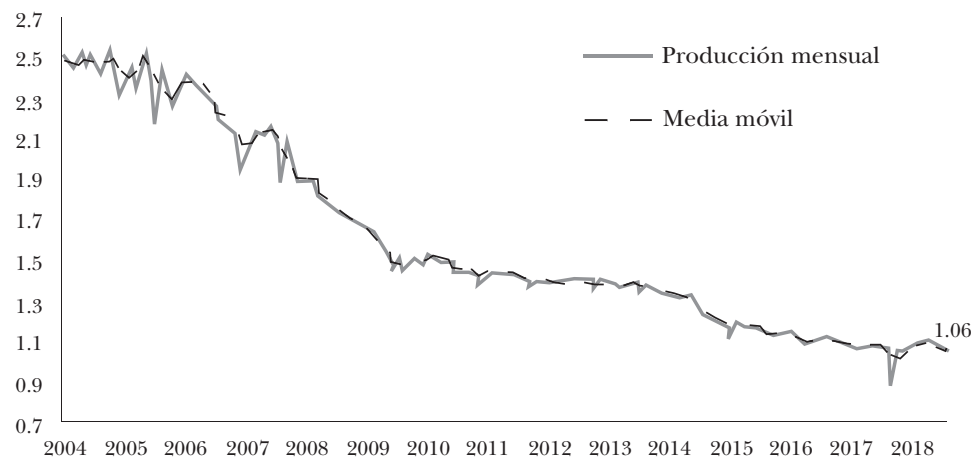

Fuente: base de datos institucional de PEMEX.

${ }^{12}$ Sener, "Rondas petroleras consolidan a México como uno de los destinos de inversión más atractivos del mundo", Boletín de prensa 041, 23 de mayo de 2017, en https://www.gob.mx/sener/prensa. 
de la menor producción y la caída de la demanda de crudo de las refinerías mexicanas, particularmente de crudo pesado. A partir de 2016, este proceso se aceleró por paros prolongados no programados en las refinerías, lo que liberó un mayor volumen de crudo pesado para la exportación. Según fueron cayendo las exportaciones, la calidad de los crudos exportados tendió a cambiar. El Maya (21-22 $2^{\circ}$ API y $3.5 \%$ de azufre), ${ }^{13}$ que originalmente provino del campo supergigante Akal, pudo mantener constantes sus principales características por un largo periodo. Con el tiempo, se convirtió en una mezcla de diversas y cambiantes corrientes de crudo. Por su parte, el Olmeca $\left(38-39^{\circ}\right.$ API), una corriente dominada inicialmente por el campo Cárdenas, también se convirtió en una mezcla, lo que afectó su rendimiento de lubricantes, perdiendo con ello la ventaja competitiva que le era propia. La mezcla de Maya se volvió más pesada al agregar crudos provenientes de KMz. Por este motivo, PEMEX decidió segregar una corriente extrapesada denominada Talám (15. $\left.8^{\circ} \mathrm{API}\right)$, que a partir de 2014 comenzó a comercializar en el Lejano Oriente y en Estados Unidos. La calidad de otros crudos, como el Istmo (32-33 $\left.{ }^{\circ} \mathrm{API}\right)$ y el Altamira (15.0-16. $\left.5^{\circ} \mathrm{API}\right)$, también varió con el tiempo. Todos estos cambios redujeron el valor relativo de los crudos mexicanos. ${ }^{14}$

${ }^{13}$ Los grados API del American Petroleum Institute son una medida de la densidad relativa de hidrocarburos líquidos.

${ }^{14}$ A lo largo del presente trabajo se emplea la clasificación de crudos utilizada por la Energy Information Administration (EIA) de Estados Unidos. El crudo pesado es de $27^{\circ}$ API o menos, los crudos intermedios son de más de $27^{\circ}$ a $35^{\circ}$ API, y los ligeros, de más de $35^{\circ}$ API. Sin embargo, en algunas publicaciones de la Agencia, los crudos pesados son de $25^{\circ}$ API o menos, límite más usual en el ámbito internacional. Utilizar la clasificación de $27^{\circ}$ API aumenta marginalmente los volúmenes comercializados de crudo pesado. Por razones estadísticas, se utiliza este límite, salvo cuando se mencione explícitamente algún otro. El Maya es, en cualquier caso, un crudo pesado, el Istmo es un crudo intermedio, y el Olmeca, uno ligero. En México, la práctica es designar el segundo como ligero y el tercero como extraligero. Los crudos de esquistos bituminosos son, casi exclusivamente, de este último tipo, aunque en Estados Unidos se los designa como ligeros. 
La modificación de la calidad de los crudos mexicanos, la formulación de sus mezclas a partir de diversas corrientes, así como las dificultades que PEMEx ha tenido y tiene para prever el volumen y la calidad del crudo disponible para la exportación, son elementos importantes que obligan a revisar la formulación de las mezclas. Se requiere urgentemente un complejo ejercicio de optimización conjunta para atender los requerimientos de las refinerías mexicanas y los flujos destinados a la exportación. Para ello, es necesario precisar las diversas restricciones a las que está sujeto el procesamiento interno de crudo, así como evaluar la demanda externa y la aceptación comercial de diferentes crudos exportables. Las fluctuaciones de la calidad del Maya, el surgimiento del Talám y las variaciones en la disponibilidad y especificaciones de crudos ligeros lo exigen.

Canadá, en cambio, mantiene un riguroso mecanismo de control de calidad del Western Canadian Select (wCS), uno de sus dos crudos de referencia. Esta mezcla de bitumen, diluyentes sintéticos, condensados y una amplia gama de corrientes de crudos convencionales y no convencionales se formuló en 2004. Se trata de un crudo de $20.5^{\circ}$ API y $3.5 \%$ de azufre. El control de calidad es indispensable para mantener su condición de crudo de referencia, respecto al cual se establecen los precios de otras corrientes de crudos pesados canadienses, otorgándose premios y descuentos según el precio de este crudo marcador. Su relevancia para el Maya, un crudo de semejante calidad, ha tendido a aumentar, al fluir un mayor volumen de crudo pesado canadiense a la costa estadounidense del Golfo. En 2017, Canadá exportó a este mercado $381 \mathrm{mbd}$ de crudo pesado, México $558 \mathrm{mbd}$ y la brecha entre ambos tiende a reducirse.

Las tendencias recientes y los prospectos de la producción petrolera de Estados Unidos y de Canadá contrastan con la evolución reciente y previsible del crudo mexicano. En Estados Unidos la extracción aumentó de 5.0 mmbd en 2008 a 9.3 mmbd en 2017. El incremento fue exclusivamente de crudos ligeros y extraligeros. Se estima que la producción en ese 
país supere los 10.7 mmbd en 2018. ${ }^{15}$ La mayor producción estadounidense permitió reducir las importaciones netas de dicho país y reiniciar la exportación de petróleo crudo en diciembre de 2015, una vez terminada la prohibición adoptada hace 40 años. En 2017, Estados Unidos exportó 1.1 mmbd de crudo. La mayor parte de este volumen tuvo como destino Canadá. A su vez, este país aumentó su producción de 3.2 mmbd en 2008 a 4.1 mmbd en 2017, principalmente de crudo pesado, que en este último año representó la mitad del total y se pronostica una capacidad de producción de 4.6 mmbd en 2020. Casi todas las exportaciones canadienses de petróleo crudo se enviaron a Estados Unidos, de las cuales el $67 \%$ era de crudo pesado. La mayor parte de estas exportaciones fluyeron a refinerías del medio oeste estadounidense y aumentaron, más recientemente, las destinadas al Golfo de México.

Conviene subrayar la naturaleza y la magnitud de los flujos de crudo entre los tres países que integran Norteamérica, así como la importación neta de hidrocarburos líquidos de la región. En 2017, según puede observarse en el cuadro 1, Canadá exportó 3.4 mmbd de petróleo crudo a Estados Unidos; a su vez, este país envió 354 mbd a Canadá y México exportó 608 mbd a Estados Unidos. El comercio de productos petrolíferos entre Canadá y Estados Unidos, si bien es importante, está bien equilibrado. En cambio, México es un importador neto significativo de estos productos, la mayor parte de los cuales proviene de Estados Unidos. Un comercio intrarregional igualmente intenso se realiza con el gas natural. Canadá es un exportador neto de hidrocarburos líquidos a Estados Unidos y éste, a su vez, un exportador neto a México. El principal flujo es, por mucho, la exportación de crudo canadiense a Estados Unidos, y el segundo, la exportación de productos petrolíferos estadounidenses a México. El enorme superávit canadiense contrasta con el déficit de México.

15 U.S. Energy Information Administration, "Short-Term Energy Outlook", octubre de 2018, en https://www.eia.gov/outlooks/steo/. 


\section{CUAdro 1}

Comercio de hidrocarburos líquidos de Estados Unidos con Canadá y México en 2017 (miles de barriles diarios)

\begin{tabular}{lrrr}
\hline & Canadá & México & Total \\
\hline Balanza & -3183 & 398 & -2785 \\
Crudo & -3092 & -608 & -3700 \\
Productos petrolíferos & -91 & 1006 & 915 \\
& & & \\
Exportaciones & 870 & 1081 & 1951 \\
Crudo & 354 & 0 & 354 \\
Productos & 517 & 1081 & 1598 \\
& & & \\
Importaciones & 4054 & 683 & 4737 \\
Crudo & 3446 & 608 & 4054 \\
Productos & 608 & 75 & 683 \\
\hline
\end{tabular}

Nota: hay errores por redondeo.

Fuente: EIA, "U.S. Imports by Country of Origin, and Exports by Destination", en https://www.eia.gov/petroleum/data.php.

Los profundos cambios registrados en los flujos de comercio y de inversión entre los tres países miembros del Tratado de Libre Comercio de América del Norte (TLCAN), particularmente los que se refieren a México, vuelven conveniente redactar y negociar un nuevo capítulo en materia de energía del Tratado. ${ }^{16}$ Para este país, una nueva estructura normativa podría dar mayor seguridad de suministro, dada la elevada y creciente dependencia de México de importaciones de productos petrolíferos y de gas natural provenientes de Estados Unidos. La integración de los sistemas energéticos de Norteamérica, la interconexión de sus redes logísticas y la interdependencia de sus mercados de energía son características singulares de la región. En el caso de Canadá y Estados Unidos la historia de estos procesos es relativamente más larga.

${ }^{16}$ El Tratado recién negociado excluyó el capítulo de energía propuesto originalmente. 
La reforma energética recientemente instrumentada por México abrió este sector a la inversión privada y a la competencia, alentando de manera decidida la integración. Según madure la reforma surgirán nuevos patrones de interacción con el sector energético mexicano. Su integración en América del Norte ha tendido a acelerarse recientemente en el marco de la caída de su producción propia de petróleo crudo y de mayores importaciones de productos petrolíferos y de gas natural. La integración no sólo amplía el tamaño del mercado de Norteamérica, sino que introduce mayor flexibilidad al suministro y permite también la autosuficiencia regional.

Según los pronósticos de la EIA, se estima que Norteamérica se convertirá en exportador neto de hidrocarburos líquidos en el año 2020. ${ }^{17}$ Esta tendencia se debe fundamentalmente al aumento de la producción de petróleo crudo de dicho país y de Canadá, que compensó con creces la caída de la producción mexicana. En 2017, Norteamérica se transformó en un exportador neto de gas natural, lo cual se explica por el hecho de que Estados Unidos, el principal productor de gas natural del mundo, redujo sus importaciones de Canadá, incrementó sus exportaciones a México y expandió sus exportaciones de gas natural licuado. Las menores exportaciones de gas de Canadá se deben a que éstas han sido desplazadas por producción estadounidense. ${ }^{18}$ Estos cambios en la balanza regional de hidrocarburos no se vislumbraban hace unos cuantos años, pero ahora ofrecen un botón de muestra del dinamismo de los flujos que vinculan a los tres países.

La diversificación geográfica de las exportaciones de petróleo crudo de México parece ir a contracorriente de los objetivos de integración energética norteamericana. Esta diversificación magnifica la pérdida de participación de mer-

17 U.S. Energy Information Administration, Annual Energy Outlook, 2017, cuadro A21, en https:/ / www.eia.gov/outlooks/aeo/pdf/0383\%2820 17\%29.pdf.

18 U.S. Energy Information Administration, "Short-Term Energy Outlook". 
cado atribuible a la reducción de su excedente exportable y desaprovecha las ventajas logísticas que se derivan de la cercanía de la región productora de la Sonda de Campeche a las refinerías de la costa estadounidense del Golfo. Asimismo, el país no se beneficia plenamente de la complementariedad industrial de su crudo pesado y la configuración de las refinerías de la costa del Golfo. La diversificación reduce además las posibilidades de vincular la adquisición de productos petrolíferos de Estados Unidos a las exportaciones de petróleo crudo mexicano, reduciendo con ello algunos riesgos de su fuerte dependencia de las importaciones. México debe aprovechar la alta y creciente capacidad excedente de refinación en la costa del Golfo para suministrar productos petrolíferos a su propio litoral y a la frontera norte, en condiciones grandemente competitivas.

Entre 2010 y 2017, Estados Unidos redujo la importación de crudos ligeros y extraligeros en más del 40\%, a causa del aumento de la producción propia proveniente de esquistos bituminosos y arenas compactas. El desplazamiento de las importaciones afectó de manera particular el suministro proveniente de México, que redirigió su exportación a Europa y Asia. Casi todos los grandes países productores perdieron participación de mercado frente a la producción interna estadounidense, pero la baja fue mucho mayor en el caso de México. Hasta ahora se carece de una explicación precisa respecto a la incapacidad de PMI de proteger mejor sus ventas de crudos ligeros en Estados Unidos durante los últimos cuatro años. En 2010, las exportaciones mexicanas de crudo Olmeca e Istmo se concentraban en América, alcanzando el $93 \%$ del total, mientras que para 2016 el $85 \%$ se dirigió a Europa y Asia. Hoy, el principal comprador de estos crudos mexicanos son refinadores del Lejano Oriente. La reducción de las ventas de Olmeca fue particularmente abrupta, iniciándose en 2014. Hasta entonces Estados Unidos era su único comprador. La mayor parte de estas ventas se desplazó a Europa, mientras que las de Istmo se dirigieron principalmente a Asia. Ahora, estos crudos mexicanos compiten 
con las exportaciones estadounidenses de crudo extraligero. En 2017, Estados Unidos exportó más de 1.1 mmbd, mientras que las ventas de PMI de crudos ligeros y extraligeros fue tan sólo de 105 mbd y en el primer semestre de 2018 descendieron a $62 \mathrm{mbd}$, después de haberse eliminado las exportaciones de Olmeca en septiembre de 2017 y las de Istmo en junio de 2018. ${ }^{19} \mathrm{El}$ impacto volumétrico de la diversificación de las exportaciones de crudo mexicano no debe subestimarse. Mientras que las exportaciones totales de petróleo crudo disminuyeron $6 \%$ entre 2012 y 2017, las que se dirigieron a Estados Unidos cayeron $36 \%$.

México se ha convertido en un país deficitario por lo que toca a los hidrocarburos. El déficit de la balanza comercial de petróleo y gas natural ascendió a 6 mil millones de dólares en 2016 y tiende a aumentar con rapidez. El déficit de 2017 fue de más de 18 mil millones de dólares. La balanza de hidrocarburos con Estados Unidos es también negativa, en este caso tanto en términos volumétricos como de valor (véase cuadro 2). Todo lo cual se explica por la reducción de las exportaciones de crudo mexicano, ampliada por la política de diversificación y por el sostenido incremento de las importaciones de productos petrolíferos y de gas natural provenientes de ese país, dada la baja de la producción de las refinerías de México y la declinante producción de gas natural. ${ }^{20}$ La exportación neta de hidrocarburos líquidos a Estados Unidos descendió a 398 mbd en 2017. El efecto compuesto de la caída de la producción y las exportaciones, no menos que del vertiginoso incremento de las importaciones de productos petrolíferos, ha resultado explosivo. A esto hay que sumar el deterioro en los términos de intercambio de crudo por productos originado en los elevados márgenes de refinación que han privado. En 2017, las importaciones totales de productos

${ }^{19}$ La exportación de ligeros y extraligeros se debe a su caída de producción a un mayor uso de este tipo de crudos para aligerar el crudo pesado y cumplir con la especificación del Maya.

20 A. Lajous, "Mexico's Hydrocarbon Dependence", Oxford Energy Forum, junio de 2017, en https://www.oxfordenergy.org/publications/. 
petrolíferos de PEMEX ascendieron a $935 \mathrm{mbd}$. De éstos, 570 mbd correspondieron a gasolinas y 237 mbd a dísel. Las importaciones del país fueron mayores, pues empresas particulares han empezado a importar directamente, sin la intervención de PMI. En algunos productos de bajo valor, como el coque de petróleo, los volúmenes son significativos desde hace tiempo. Destaca el hecho de que la gasolina importada contribuyó con el $71 \%$ de las ventas internas y las del dísel con el $66 \%$.

\section{Cuadro 2}

Balanza comercial de hidrocarburos líquidos de Estado Unidos con México entre 2014 y 2017 (miles de barriles diarios)

\begin{tabular}{lrrrr}
\hline & 2014 & 2015 & 2016 & 2017 \\
\hline Balance & 283 & 68 & -210 & -398 \\
Importaciones totales & 842 & 758 & 669 & 683 \\
$\quad$ Petróleo crudo & 781 & 688 & 582 & 608 \\
$\quad$ Productos & 61 & 70 & 87 & 75 \\
& & & & \\
Exportaciones totales & 559 & 690 & 880 & 1081 \\
$\quad$ Gasolinas* & 261 & 331 & 427 & 495 \\
Dísel & 128 & 143 & 182 & 256 \\
GLP** & 66 & 91 & 122 & 143 \\
& & & & \\
Turbosina & 13 & 4 & 33 & 41 \\
Combustóleo & 24 & 26 & 30 & 40 \\
Coque de petróleo & 35 & 43 & 52 & 68 \\
Otros & & & & \\
\hline
\end{tabular}

* Gasolina y componentes.

** GLP y otros líquidos del gas.

Fuente: EIA, "U.S. Imports by Country of Origin, and Exports by Destination".

La dinámica del desequilibrio con Estados Unidos obedece en gran medida al crecimiento de las importaciones de combustibles automotrices de las refinerías de la costa del 
Golfo. Para éstas, las ventas a México han sido una fuente de atractivos negocios, que les ha permitido mantener niveles récord de utilización de la capacidad instalada. En 2017, cerca de la mitad de las exportaciones estadounidenses de gasolinas y sus componentes tuvo como destino México. Asimismo, el surgimiento de Estados Unidos como exportador de crudo ligero es un desarrollo de enorme trascendencia. En 2017, las exportaciones de crudo estadounidenses ascendieron a 1.1 mmbd, mientras que el volumen exportado por México fue de 1.2 mmbd y a muy corto plazo las superará por un amplio margen. El crecimiento de las exportaciones de crudo ligero de dicho país amplía el volumen de crudo pesado que pueden importar las refinerías del Golfo, haciendo más pesada su carga, lo cual beneficia tanto a las refinerías que fueron diseñadas para procesar crudo pesado como a los países que lo exportan.

\section{Mercado de CRUdo Pesado}

Hace quince años, Juan Carlos Boué caracterizó el mercado de crudo pesado amargo de la costa estadounidense del Golfo de México, analizó detalladamente su estructura, develó la conducta del duopolio formado por PEMEX y Petróleos de Venezuela (PDvsa) y explicó la determinación y el comportamiento de sus precios de exportación. Los cambios fundamentales registrados a partir de entonces merecen un nuevo estudio de alcance y ambición similares, que ponga al día su trabajo innovador. ${ }^{21}$ En este artículo, sólo se esbozan algunos de estos cambios para circunstanciar la declinación y las perspectivas de las exportaciones de crudo Maya en este mercado.

${ }^{21}$ Boué, con la colaboración de L. Figueroa, The Market for Heavy Sour Crude Oil in the US Gulf Coast. The Pemex/Pdvsa Duopoly, Oxford, Institute for Energy Studies, 2002. 
Se ha iniciado en la costa del Golfo un ciclo de escasez relativa de crudo pesado que podría extenderse, por lo menos, al 2020. Una menor producción y exportación de crudo de Venezuela y de México son los principales determinantes de esta tendencia, si bien Colombia y Brasil también han contribuido a este comportamiento cíclico. Las restricciones en la capacidad de transporte de Canadá al Golfo limitan el flujo de este país y las exportaciones de crudo pesado iraquí (Basrah Heavy, 24.7 ${ }^{\circ}$ API) y de Árabe Pesado Saudita $\left(27^{\circ}\right.$ API) están también restringidas. En el primer caso, dicho país no puede aumentar la disponibilidad en el Golfo sin reducir sus ventas a Asia. En el caso saudita, mientras la producción esté sujeta a cuotas de la opep, la exportación de crudo pesado de menor precio se verá constreñida.

La escasez de crudo pesado aumentará por la acelerada caída de la producción venezolana. Las consecuencias de las sanciones estadounidenses, un desequilibrio macroeconómico profundo, el deterioro de las condiciones operativas de la industria petrolera, así como una dinámica política y social particularmente conflictiva, son fuente de incertidumbre respecto a la producción futura, a corto y mediano plazos, de Venezuela. Hasta 2017, este país continuaba siendo el principal suministrador de crudo pesado de las refinerías del Golfo. Interrupciones potenciales de su oferta petrolera y la necesidad de colocar mayores volúmenes de crudo en China y Rusia, sus principales acreedores, podría reducir aún más las exportaciones a Estados Unidos. De hecho, en el cuarto trimestre de 2017 y la primera mitad de 2018, la producción venezolana sufrió una contracción significativa.

México se ha especializado por largo tiempo en la producción y la exportación de crudo amargo pesado. Su importancia es inequívoca a pesar de la reducción del volumen producido. En 2017, el 54\% de la producción fue de crudo pesado y el $91 \%$ de la exportación total. En 2004, las exportaciones mexicanas de este tipo de crudo alcanzaron un pico de $1.6 \mathrm{mmbd}$, un monto equivalente al $87 \%$ del total exportado. En 2017, este volumen cayó a 1.1 mmbd. Por su lado, 
las refinerías estadounidenses han tendido a aumentar la importación de crudo pesado. La exportación de crudos ligeros y extraligeros de México disminuyeron más lentamente, porque su producción se sostuvo y las refinerías del país procesaron un mayor volumen de crudo pesado gracias a la reconfiguración de tres de ellas -Cadereyta, Ciudad Madero y Minatitlán-, en las que se construyeron plantas de conversión profunda.

A su vez, Estados Unidos es, por mucho, el principal consumidor de crudo pesado del mundo. Cuenta con una enorme capacidad de proceso de plantas coquizadoras que permiten obtener mayor valor de crudos pesados de menor precio. El $55 \%$ de la capacidad instalada de coquización en ese país se encuentra en las refinerías de la costa del Golfo. La participación de las importaciones de crudo pesado (de $25^{\circ}$ API o menos) aumentó de $19 \%$ en 1990 a $56 \%$ en 2017 . El volumen de las importaciones de este crudo continuó creciendo a pesar de que el volumen total de las importaciones estadounidense disminuyó de manera significativa entre 2005 y 2017. Así, las importaciones de crudo pesado lograron alcanzar un volumen pico de $4.4 \mathrm{mmbd}$ en ese último año. ${ }^{22}$

El excedente exportable de crudo pesado mexicano producido mar adentro y los crecientes requerimientos de este tipo de crudos en Estados Unidos, en particular de las refinerías de la costa del Golfo, constituyen flujos complementarios unidos por una cadena logística excepcional. Su bajo costo de transporte y el hecho de que el periodo de entrega de los embarques provenientes de la Sonda de Campeche es más corto que el que se tiene usualmente por oleoducto en su mercado interno, dados los tiempos de programación requeridos por este medio de transporte. Asimismo, la complementariedad industrial obedece a que un buen número de plantas coquizadoras que entraron en operación en el Golfo

${ }^{22}$ Eia, "Percentage of Total Imported Crude Oil by API Gravity and Downstream Charge Capacity of Operable Petroleum Refineries", en https://www.eia.gov/dnav/pet/pet_move_ipct_k_m.htm. 
entre 1995 y 2005 fueron específicamente diseñadas para procesar crudo Maya.

Hay un robusto sistema de oleoductos que une la cuenca sedimentaria del oeste de Canadá con mercados estadounidenses de petróleo crudo. Su expansión reciente ha permitido llevar volúmenes crecientes de crudo pesado a refinerías situadas en la costa del Golfo. Un volumen relativamente modesto también ha sido transportado por carro de ferrocarril a este mercado. En 2017, el 51\% de las importaciones estadounidenses de este tipo de crudo provino de Canadá, concentrándose en el Medio Oeste. Las importaciones mexicanas de este tipo de crudo sólo representaron el 13\% del total, aunque su participación de mercado en el Golfo ascendió a $26 \%$. Todas las importaciones de México llegaron por vía marítima, mientras que las canadienses cruzaron grandes distancias por vía terrestre.

La expansión de la producción de Alberta, así como de la capacidad de los oleoductos que transportan crudo pesado canadiense a la costa del Golfo, han permitido ocupar buena parte del espacio abierto por la menor exportación de México y de Venezuela a esta región. El desplazamiento -obligado o voluntario- del crudo de estos dos países facilitó la entrada de mayores volúmenes de crudo pesado canadiense al Golfo. Ante el aumento de la producción de crudos extraligeros en Estados Unidos, corrientes de crudo canadiense más pesado que el Maya permiten procesar una mayor proporción de crudo ligero estadounidense en sus refinerías. Para Canadá, una vez saturada la capacidad de coquización de su crudo en las refinerías del medio oeste estadounidense, la única salida a corto plazo del crudo pesado de Alberta es la costa del Golfo. Sólo mediante la ampliación y construcción de oleoductos a su costa occidental contaría con una ruta alterna de evacuación de su producción tierra adentro. Mientras tanto, conviene a Canadá exportar al Golfo hasta el límite de la capacidad de transporte existente, al precio que sea necesario para llenar dichos oleoductos. Contar con una ruta directa más robusta a la costa canadiense del Pacífico abre la posibi- 
lidad de una mayor exportación a Asia y a la costa occidental de Estados Unidos después de 2020, lo que temperaría la competencia en el mercado del Golfo. Sin embargo, tendrá que disponer de suficiente capacidad de producción de crudo para justificar económicamente la construcción de múltiples oleoductos actualmente bajo consideración, incluido el Keystone XL. Así, la disponibilidad de crudo pesado canadiense y el calendario de la entrada en operación de los oleoductos que incrementarán el flujo de crudo pesado a la costa del Golfo son cruciales para México.

\section{CUADro 3}

Suministro de petróleo crudo de Canadá a oleoductos troncales y mercados entre 2016 y 2025

(miles de barriles diarios)

\begin{tabular}{lcccccc}
\hline & $2016^{*}$ & 2017 & 2018 & 2019 & 2020 & 2025 \\
\hline Total & 3.9 & 4.1 & 4.4 & 4.5 & 4.6 & 4.9 \\
Pesado & 2.7 & 2.9 & 3.2 & 3.3 & 3.4 & 3.7 \\
(Alberta) & & & & & & \\
\hline
\end{tabular}

*Real.

Fuente: Canadian Association of Petroleum Producers, "Crude Oil Forecast, Markets, \& Transportation", 2017, en https://www.capp.ca/publications-and-statistics/publications/303440.

El supuesto básico que subyace en estos pronósticos es que los incrementos de la producción hacia 2020 provendrán de proyectos que iniciaron operaciones en ese plazo y los que están en estado avanzado de construcción. Para años posteriores, se consideran nuevos proyectos que aún no han recibido su aprobación final, por lo que están sujetos a mayor incertidumbre, dado el nivel actual de precios del crudo y sus elevados costos. Las proyecciones de producción total hacia 2025 son consistentes con las del National Energy Board de Canadá y el EIA de Estados Unidos. En 2018, se inició un periodo de cuando menos 3 años en los que el flujo de la 
producción de crudo pesado canadiense a Estados Unidos enfrentará crecientes restricciones de capacidad, lo que obligará a una mayor utilización del transporte por ferrocarril.

En 2019, entrarán en operación dos oleoductos: el proyecto de remplazo de la Línea 3 de Enbridge incrementará la capacidad de transporte de 390 a $760 \mathrm{mbd}$, si bien se estima que sólo el 20\% del incremento se utilizará para transportar crudo pesado y el oleoducto Trans Mountain de Kinder Morgan, cuya capacidad aumentará de 300 a $890 \mathrm{mbd}$, tenía previsto entrar en operación en diciembre de 2019, cuya construcción, sin embargo, ha sido interrumpida por restricciones legales y regulatorias. Después de esta fecha, no hay otros proyectos que inicien operaciones, aunque el flujo de crudo podría aumentar mediante mejoras operativas y de optimización de rutas en el sistema de gasoductos. Mientras tanto, la capacidad excedente desaparecerá y el sistema se congestionará, aumentando el descuento del wcs. El tramo del oleoducto Keystone XL de TransCanada, que llega hasta Steel City, Nebraska, fue aprobado en noviembre de 2017. Sin embargo, el regulador rechazó el trazo preferido por TransCanada y propuso una alternativa, lo cual probablemente afecte nuevamente el inicio de la construcción en 2018 y el arranque de las operaciones en 2021. Este oleoducto aumentaría la capacidad de transporte hasta el Golfo en aproximadamente $830 \mathrm{mbd} .^{23}$

La exportación de crudo canadiense a la costa del Golfo por ferrocarril está limitada por su elevado costo y por la capacidad de manejo. En julio de 2017, de un flujo total de 390 mbd sólo $21 \mathrm{mbd}$ utilizaron este medio de transporte, un monto ligeramente superior al 5\%. Las restricciones de capacidad de los oleoductos obligarán a hacer mayor uso de carro-tanques. Sin embargo, es difícil estimar el volumen que efectivamente se transportará por este medio en los próximos tres años. Asimismo, la insuficiente capacidad de transporte del Oeste de Texas a la costa del Golfo deprime los

23 Canadian Association of Petroleum Producers, informe citado, pp. 23-25. 
precios del wTI, lo que explica la ampliación de su diferencial respecto al precio del Brent.

Proyectar a mediano plazo el balance de crudo pesado en la costa del Golfo es tarea difícil, dado el número de factores que estarán sujetos a cambio en ese periodo. Destacan, entre ellos, la trayectoria de los precios del crudo; la capacidad de transporte por oleoducto; la disponibilidad de crudo en Canadá, México y Venezuela; la demanda de este tipo de petróleo de las refinerías de la costa del Golfo; la restricción de emisiones anticipadas de bióxido de carbono $\left(\mathrm{CO}_{2)}\right.$ de la producción de arenas bituminosas en Canadá. El nivel de precios del WTI determinará, en gran medida, la producción de Canadá, dado el alto costo de producción de estas arenas en Alberta. Precios del wTI de 65 dólares por barril difícilmente permitirán ampliar la producción en esa provincia petrolera más allá de la capacidad prevista de proyectos en ejecución.

Canadá es, por mucho, el principal suministrador individual de petróleo crudo de Estados Unidos. En 2017, exportó a dicho país más que los países miembros de la OPEP en conjunto. Es notable que Canadá y México hayan suministrado en ese año el $49 \%$ del total de crudo importado y el $63 \%$ del crudo pesado. Las importaciones estadounidenses de este tipo de crudo aumentaron a un ritmo modesto a lo largo del periodo 2009-2017, al pasar de 4.0 a $4.7 \mathrm{mmbd}$. En este plazo, casi todo el incremento se registró en las refinerías del Medio Oeste, donde iniciaron operaciones un buen número de coquizadoras. Este mercado es suministrado exclusivamente por Canadá. En cambio, en las coquizadoras de las refinerías del Golfo, que habían sido construidas anteriormente, el procesamiento de crudo pesado disminuyó levemente, si bien continúan adquiriendo el $45 \%$ del crudo importado de este tipo. El origen de las importaciones del Golfo se concentra en el hemisferio occidental y, dentro de éste, en tres países: Canadá, Venezuela y México. Durante un buen número de años, el 93\% de estas importaciones provino del propio continente americano, si bien en fechas recientes aumentó el suministro de países del Golfo Pérsico, en particular de crudo 
Basrah Heavy, producido por Irak. Con todo, en 2017 el 82\% del crudo pesado importado se originó en América. Cabe señalar que Estados Unidos produce sólo un volumen pequeño de crudo pesado de $25^{\circ}$ API o menos. Éste asciende, aproximadamente, a $6 \%$ de la producción de dicho país y la mayor parte se extrae en California, donde se procesa.

Para 2017, aumentó la capacidad de producción de crudo de Alberta destinado a la exportación en 200 mbd y en 2018 deberá ampliarse en unos 300 mbd más. Se trata de un incremento sustancial respecto a lo que se destinó al Golfo en 2016. Gran parte de este volumen fluiría al mercado del Golfo, en caso de que haya mayor capacidad de transporte disponible. Los oleoductos para exportación de crudo de la cuenca sedimentaria occidental de Canadá operan actualmente al límite de su capacidad. De una capacidad instalada de $4 \mathrm{mmbd}$ se estima contar con una capacidad efectivamente disponible de $3.3 \mathrm{mmbd} .{ }^{24}$ Es posible que el flujo de crudo al Golfo pueda aumentar modestamente por un uso más eficiente de la capacidad instalada. Reflejo de ello es el incremento de las exportaciones a la costa del Golfo de 333 mbd en el segundo semestre de 2016 al primero de 2017 de $384 \mathrm{mbd}$, un incremento de 14\%. El siguiente incremento significativo de la capacidad de transporte se dará después de 2022. PMI debe prepararse desde ahora para hacer frente al posible aumento de la oferta de crudo pesado en el Golfo. Se trata de un periodo de unos 4 años.

Entre 2009 y 2017, se dio un cambio importante en las participaciones de mercado de los tres principales suministradores de la costa del Golfo, como puede verse en el cuadro 4. Venezuela, a pesar de la erosión de su capacidad de producción y de sus malas relaciones con el gobierno y las empresas petroleras estadounidenses, logró una participación de $32 \%$ al principio de este periodo, alcanzó una participación de $36 \%$ en 2012 y ésta descendió a 28\% en 2017. México, en cambio, vio su participación caer en este mismo periodo de 41 a

${ }^{24}$ Ibid., p. 30. 
26\%. En su caso, la caída de las exportaciones de crudo pesado fue ampliada por un esfuerzo deliberado de diversificar sus exportaciones de Maya en Europa y Asia. La pérdida de mercado de México fue tomada íntegramente por Canadá, que aumentó su participación de 4 a $18 \%$ entre 2009 y 2017 y más recientemente por Irak, que elevó su participación al 10\%.

En el cuadro 4, figuran los principales países que exportan crudos pesados a Estados Unidos y, en particular, a la costa del Golfo. Puede observarse que esta región absorbió el $45 \%$ del crudo pesado importado por Estados Unidos y que el $79 \%$ del crudo que se importó a esta región provino de cuatro países, todos del hemisferio occidental. Reluce el hecho de que Canadá sólo exporta al Golfo el 15\% del crudo que envía a Estados Unidos por consideraciones logísticas y que el crudo ecuatoriano tiene como principal destino la costa occidental de dicho país. Otra fuente potencial de crudo pesado es Irak. Sus exportaciones totales de Basrah Heavy ascienden a unos 810 mbd y tienen a Asia por su principal destino. De esta corriente, fluyen unos $165 \mathrm{mbd}$, aproximadamente el $20 \%$ a refinerías del Golfo.

Desde 2012 hasta 2017, la baja de las exportaciones de crudo pesado mexicano a refinerías del Golfo se acompañó de un reordenamiento del volumen asignado a sus principales clientes. Una menor cantidad se dispersó entre diversos compradores, reduciéndose a más de la mitad el monto retirado por grandes refinadores como Exxon, Chevron y Phillips. Como era de esperarse, se mantuvo el abastecimiento de Deer Park -la coinversión entre Shell y PEMEx- que en principio podría procesar hasta la mitad de su carga con crudo Maya, estimándose originalmente una entrega del orden de 200 mbd. Según la EıA, los envíos a Deer Park entre 2013 y 2017 se mantuvieron ligeramente por abajo de $170 \mathrm{mbd}$, cerca del volumen contractual enmendado. ${ }^{25}$ Otros contratos de crudo Maya a plazo ajustaron su volumen a la baja. Éste

25 En septiembre de 2018 se renegoció este contrato y se redujo el volumen pactado. 
ha sido el caso de los que PMI suscribió con Valero, Houston Refining, a más de otros cuatro clientes.

\section{CuAdro 4}

Participación de mercado de importaciones de crudo pesado* de Estados Unidos entre 2009 y 2017 (porcentajes)

\begin{tabular}{lccc}
\hline & 2009 & 2012 & 2017 \\
\hline Crudo pesado/ Total US & 43 & 48 & 59 \\
Pesado Golfo/ Total US pesado & 58 & 56 & 45 \\
Américas/ Total Golfo & 93 & 93 & 82 \\
Tres principales países/ Total Golfo & 77 & 74 & 72 \\
Venezuela & 32 & 36 & 28 \\
México & 41 & 32 & 26 \\
Canadá & 4 & 5 & 18 \\
\hline
\end{tabular}

*Densidad específica de $27^{\circ}$ API o menos.

Fuente: EIA, "Crude Imports", en https://www.eia.gov/petroleum/ imports/browser/.

\section{CuAdro 5}

Importaciones estadounidenses de crudo pesado de países seleccionados, total y costa del Golfo, durante 2017 (miles de barriles diarios)

\begin{tabular}{lcr}
\hline & EE. UU. & Golfo \\
\hline Total & 4693 & 2131 \\
Canadá & 2472 & 381 \\
México & 602 & 558 \\
Venezuela & 601 & 587 \\
Colombia & 293 & 149 \\
Irak & 242 & 203 \\
Ecuador & 190 & 2 \\
Brasil & 117 & 97 \\
Chad & 26 & 18 \\
Angola & 9 & 14 \\
& & \\
Otros & 131 & 122 \\
\hline
\end{tabular}

Fuente: EIA, "Crude Imports". 
Entre 2012 y 2016, las ventas de crudo pesado de PMI a las refinerías del Golfo cayeron $175 \mathrm{mbd}$, es decir una baja de 24\%. De este volumen, cuatro refinadores -Exxon, Valero, Chevron y Phillips- redujeron compras a México por 214 mbd. En el mismo periodo, estas cuatro empresas aumentaron sus compras en Canadá (77 mbd), Irak (70 mbd) y Venezuela (57 mbd), es decir un total de $204 \mathrm{mbd}$. Phillips tuvo que sustituir las compras que anteriormente hacía en Venezuela con crudo canadiense e iraquí; Valero compró más crudo en Venezuela y Canadá; y Chevron lo hizo en Venezuela e Irak. Las refinerías de Exxon han reducido sustancialmente sus adquisiciones de crudo pesado hasta llegar en 2016 a sólo 200 mbd. Pmi, a pesar de la caída de sus ventas para esta empresa, fue su principal suministrador, seguido de Canadá. Va a ser difícil recuperar la pérdida volumétrica y de participación de mercado sufridas por México en la costa del Golfo, pues este espacio comercial ha sido ocupado por otros proveedores. PMi va a tener que desplegar un importante esfuerzo de ventas para desplazar a algunos de ellos y restituir, cuando menos en parte, el volumen perdido por la estrategia de diversificación. El reto es particularmente desafiante dada la incertidumbre respecto al volumen firme disponible de Maya para exportación.

La producción petrolera de Venezuela disminuyó de 2.7 a 2.0 mmbd entre 2014 y 2017, es decir una baja de 700 mbd. ${ }^{26}$ Para octubre de 2016, tanto Venezuela como México habían cruzado, a la baja, el umbral de producción de 2.0 mmbd. En estas circunstancias, resulta un tanto paradójico que su participación de mercado en la costa del Golfo haya logrado mantenerse relativamente estable, si bien las exportaciones venezolanas a Estados Unidos declinaron en años

${ }^{26}$ Estas cifras fueron proporcionadas por el gobierno de Venezuela directamente al secretariado de la OPEP. OPEc, "Monthly Oil Market Report", octubre de 2018, en https://www.opec.org/opec_web/en/publications/338.htm. Las cifras estimadas por fuentes secundarias difieren en cuanto al volumen absoluto, pero la reducción registrada en ambas es muy similar. En septiembre de 2018 esta cifra había descendido a $1.4 \mathrm{mmbd}$. 


\section{Cuadro 6}

Importaciones estadounidenses de petróleo crudo pesado por refinerías seleccionadas del Golfo entre 2012 y 2016 (miles de barriles diarios)

\begin{tabular}{lrrc}
\hline & 2012 & 2017 & Variación \% \\
\hline Total & 731 & 557 & -24 \\
Deer Park (Houston) & 185 & 152 & -18 \\
Valero (Port Arthur \&Texas City) & 165 & 90 & -45 \\
Houston Refining (Houston) & 23 & 82 & 257 \\
Chevron (Pascagoula) & & & -29 \\
Phillips (Lake Charles**) & 90 & 64 & -13 \\
Exxon (Baytown*) & 137 & 52 & -66 \\
& & 46 & 143 \\
Total (Port Arthur) & 7 & 17 & -50 \\
Marathon (Garyville***) & 30 & 15 & -29 \\
Hunt (Tuscaloosa) & 14 & 10 & -3 \\
Otros & 30 & 29 & -6 \\
\hline Memorandum & & & \\
$\quad$ Importaciones totales & 2261 & 2131 & \\
\hline
\end{tabular}

* Incluye Baton Rouge and Baumont en 2012.

** Incluye Sweeny en 2012.

*** Incluye Galveston Bay.

Fuente: EIA, "Heavy Crude Imports", PADD3, en https://www.eia. gov/petroleum/imports/browser/.

recientes, lo cual se explica parcialmente por la reducción del nivel de proceso de las refinerías de ese país, dada la caída de la demanda interna y la necesidad apremiante de colocar petróleo crudo en Estados Unidos que fuera liquidado oportunamente. Sin embargo, aumenta la posibilidad de que la producción total y las exportaciones venezolanas al Golfo caigan abruptamente, como resultado de la crisis económica, financiera y social por la que atraviesa este país y la forma como ésta se resuelva con el tiempo. Además, la imposición 
de sanciones norteamericanas a ese país y el posible default venezolano podrían acelerar la caída de la producción. ${ }^{27}$

El 24 de agosto de 2017, el gobierno de Estados Unidos amplió el régimen de sanciones impuesto a Venezuela, prohibiendo diversas transacciones financieras a personas físicas y morales estadounidenses o que se realicen en Estados Unidos. Sin embargo, la orden ejecutiva del presidente estadounidense también prevé un conjunto de excepciones mediante el otorgamiento de licencias o autorizaciones de carácter general. Previamente, el gobierno estadounidense había impuesto sanciones individuales al presidente Maduro y a un hermano de Hugo Chávez, ocho magistrados del Tribunal Superior y trece altos funcionarios del gobierno venezolano.

El objeto principal de estas sanciones es restringir el acceso de Venezuela al mercado de capitales y enviar una señal clara a las instituciones financieras con respecto de las transacciones con dicho país. Sin embargo, no tocan el amplio comercio de petróleo crudo y productos petrolíferos entre Estados Unidos y Venezuela, ni tampoco las actividades de Citgo en aquél. Poco afectan las transacciones financieras entre ambos países, ya que desde hace tiempo se agotó el acceso de Venezuela a los mercados crediticios de Estados Unidos, dada su precaria situación económica y financiera. En cambio, para la industria de refinación estadounidense la estabilidad del flujo de crudo pesado venezolano es crucial, incluido el suministro a las refinerías de Citgo. El carácter eminentemente político de las sanciones resulta transparente. Dejan a Venezuela en una posición vulnerable en un trayecto que muy probablemente la lleve a un default (suspensión de pagos).

El monto y la diversidad de sus obligaciones externas plantean un conjunto de problemas particularmente complejo. En 2017, dichas obligaciones se estimaban en 196 mil

${ }^{27}$ Las sanciones no permiten a Venezuela obtener cartas de crédito para la importación de diluentes, lo que impide a PDVsa cumplir con las especificaciones de sus crudos y afecta el volumen del crudo exportado. 
millones de dólares, cifra equivalente a $150 \%$ del PIB. Del total, aproximadamente 120 mil millones correspondían a endeudamiento financiero y a ventas anticipadas de petróleo. El resto es deuda con suministradores y contratistas. Los bonos no garantizados por el gobierno sumaban cerca de 36 mil millones de dólares y los bonos de PDVsA, otros 27 mil millones. La empresa petrolera estatal colocó bonos garantizados con el $50.1 \%$ de las acciones de Citgo, su subsidiaria estadounidense. China y Rusia mantenían 28 mil y 9 mil millones de pasivos de Venezuela, respectivamente. Los pasivos con suministradores y contratistas ascendieron a cerca de 60 mil millones de dólares. ${ }^{28}$

Las difíciles condiciones que han prevalecido en Venezuela durante los últimos 10 años abrieron la posibilidad de que China y más tarde Rusia pudieran vincularse más directamente con la industria petrolera de dicho país. Ambos asumieron una perspectiva estratégica de largo plazo en su acercamiento a Venezuela y sus recursos naturales. China ha otorgado créditos por un total de 62 mil millones de dólares a Venezuela para proyectos principalmente en el sector energético. ${ }^{29}$ China National Petroleum Corporation (CNCP) participa en coinversiones con PDVsA en el Orinoco y en otras regiones y ha hecho préstamos garantizados con la exportación de petróleo y productos petrolíferos. Debe anotarse que en fechas recientes el flujo de inversiones ha disminuido drásticamente.

La empresa rusa Rosneft ha invertido cuantiosos recursos en Venezuela por medio de diversos canales. Mantiene el 49.9\% de las acciones de Citgo como aval de un crédito de 1.5 miles de millones de dólares que otorgó a PDvsA. Venezuela recibió también en 2017 mil millones de dólares que serán

${ }^{28}$ M. A. WALKer y R. J. CoOper, "Venezuela's Restructuring: A Realistic Framework", septiembre de 2017, en https:/ / www.millsteibandco.com/ news.

${ }^{29}$ K. Gallagher y M. Myers, "China-Latin America Finance Database”, Washington, D. C., Inter-American Dialogue, 2016, en https://www. thedialogue.org/map_list/. 
cubiertos con ventas anticipadas de crudo y productos petrolíferos. Rosneft ha invertido en cinco proyectos de producción petrolera de gran tamaño. En noviembre de 2017, el gobierno venezolano reestructuró deuda por 3.15 miles de millones de dólares con Moscú, lo cual le permitió pagar intereses sobre su deuda por algún tiempo. En diciembre pasado, Rosneft otorgó a Venezuela licencias a treinta años para el desarrollo de dos campos mar adentro de gas no asociado. Aparentemente negocia una participación en otros proyectos en el Orinoco que sustituirían el aval otorgado de Citgo, lo cual reduciría las complicaciones que podrían surgir a raíz de las sanciones estadounidenses y otros problemas legales, en caso de que Rosneft se viera obligado a liquidar su posición en Citgo. Tanto Rusia como China están plenamente conscientes de los riesgos que correrían en caso de un default venezolano y de un posible cambio de régimen en ese país. Recientemente, PDVsa redujo sus ventas de crudo en el Golfo, incluido Citgo, pues necesita incrementar sus envíos a estos dos países para compensar el rezago acumulado del repago de sus ventas anticipadas.

El shock de una suspensión parcial o total del suministro venezolano afectaría severamente el balance global de crudo y, de manera particular, el abasto de crudo pesado a las refinerías del Golfo. El impacto dependería crucialmente del monto, la duración y la incertidumbre asociados a la interrupción. Ésta sólo podría atenuarse con mayores exportaciones de Canadá y México a la costa del Golfo y, en menor medida, con volúmenes de crudo pesado provenientes de otras fuentes. Conviene recordar que Venezuela envía a este mercado aproximadamente $600 \mathrm{mbd}$. México podría regresar a su mercado tradicional del Golfo una parte de las exportaciones que destina a otras regiones. En esas circunstancias, la demanda excedente de crudo pesado reduciría significativamente el diferencial de precios entre crudos ligeros y pesados e incrementaría los precios del crudo pesado en el Golfo. Convendría que México contara con mayor flexibilidad contractual para llevar a cabo estos desplazamientos y así aprovechar la 
oportunidad para reordenar el destino de sus exportaciones, a fin de maximizar el ingreso derivado de éstas.

La escasez de crudo pesado y la abundancia relativa de ligero en la costa del Golfo ha reducido el diferencial de precios entre estos dos tipos de crudo (véase gráfica 4). Este diferencial ha tendido recientemente a aumentar por razones que tienen que ver con la operación de la fórmula de precios del Maya. Dada su importancia, una reducción súbita de crudo venezolano obligaría a los refinadores de esta región a buscar crudo pesado en todas las fuentes posibles. El diferencial de precios de crudos ligeros y pesados incluso podría desaparecer, lo cual alentaría la oferta de crudos pesados, en particular en los países que han restringido la producción de éstos, a causa de los recortes asociados a las cuotas establecidas por la opeP. Los refinadores de la costa del Golfo acudirían, en primera instancia, a los países donde actualmente se surten; más adelante buscarán desviar a esta región importaciones de crudo pesado de otros mercados estadounidenses y de otros países, apoyándose en menores diferenciales de precios entre crudos pesados y ligeros; y se alentaría, llegado el momento, una mayor producción de crudo pesado.

\section{Perspectivas de LA PRODUCGión}

DE CRUdo PESADO EN MÉXICo

La producción de crudo pesado cayó de 2.5 a $1.1 \mathrm{mmbd}$ entre 2004 y 2017, es decir una reducción porcentual de $60 \%$. El avasallador colapso de Akal -el campo dominante del complejo Cantarell- sólo fue parcialmente compensado por la expansión de KMz. Mientras que Akal se desplomó de 2.0 mmbd en 2004 a 370 mbd en 2010 y a 55 mbd en 2017, una caída acumulada de 97\%, KMz aumentó su producción de 301 a 829 mbd entre 2004 y 2010, cuando tendió a estabilizarse. Es posible que haya alcanzado una producción máxima de 855 mbd en 2013. Las perspectivas 
a corto y mediano plazos de la producción y de la exportación de crudo pesado, así como de su calidad, son inciertas. Tres proyectos determinarán la producción en este horizonte temporal y, más adelante, en la primera mitad de los años veinte. Un patrón de declinación gradual de $\mathrm{kMz}$, el desarrollo de la producción de crudos extrapesados en aguas someras de la Sonda de Campeche y la correspondiente al proyecto de expansión en Ayatsil-Batsil, también en aguas someras. Otras fuentes de crudo pesado podrán surgir como resultado de las actividades que realizan PEMEx y otras empresas operadoras mar adentro en el Golfo de México que, de resultar exitosas, ofrecerán producción adicional a más largo plazo. ${ }^{30}$

A la inversa de Akal, que alcanzó su producción máxima e inmediatamente comenzó a declinar, KMz ha logrado mantener una producción relativamente estable por un periodo de siete años. Sin embargo, es pertinente observar las diferentes trayectorias de cada uno de los campos que lo conforman. La producción máxima de $\mathrm{Ku}$ se registró en 2009, seguida por Zaap en 2014 y es muy posible que Maloob esté por alcanzar o haya alcanzado ya su pico de producción. Este patrón no sólo contribuyó a la estabilidad de la producción, sino que hace más factible que la declinación de kMz sea más gradual que la de Akal. La dinámica descrita de la producción modificó la calidad del crudo extraído, haciéndolo cada vez más pesado, dado que Maloob y Zaap producen crudos de mayor densidad que $\mathrm{Ku}$. El comportamiento del volumen y de la calidad de crudo de KMz es crucial, puesto que en 2017 el 77\% de la producción de crudo pesado del país provino de este complejo, que contribuyó a una proporción aún mayor que las exportaciones de crudo pesado. Otros campos marinos aportaron el $16 \%$ de la producción y campos terrestres el $6 \%$ restante.

${ }^{30}$ Ejemplo de ello es el descubrimiento reciente del campo Amoca en aguas someras, que contiene crudo de $25^{\circ}$ API. 
GrÁficA 2

Producción de PEMEx de petróleo crudo y cambios volumétricos por origen entre 2004 y 2017

(miles de barriles diarios)

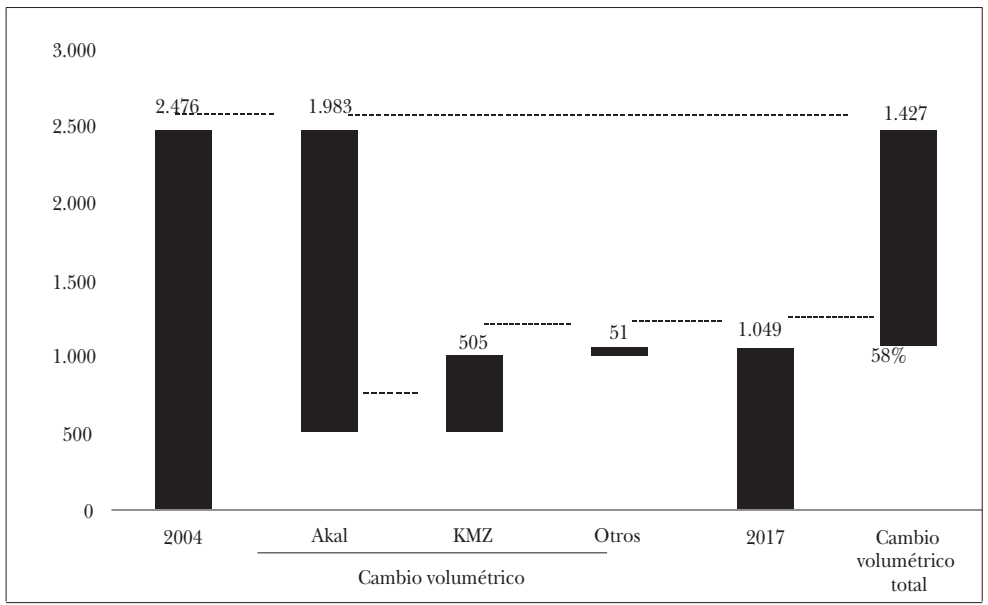

Fuente: base de datos institucional de PEMEx.

La relación entre las tasas de declinación, de agotamiento y de remplazo de la producción es importante para explicar la evolución reciente y futura de la producción en KMz. ${ }^{31}$ Ésta ya alcanzó su plataforma máxima, aunque la tasa de declinación observada es hasta ahora lenta. En 2016, las reservas probadas de estos tres campos disminuyeron 235 millones de barriles, ya que sólo fue posible restituir el 23\% de la producción. En 2017, estas reservas nuevamente disminuyen, la tasa de agotamiento del complejo se elevó a 15\%, si bien hay fuertes diferencias entre los tres campos: las tasas de agotamiento de las reservas probadas remanentes de Ku, Zaap y

${ }^{31}$ La tasa de agotamiento es la producción anual dividida por el volumen de las reservas al final del año. Para el corto plazo, es importante tomar sólo las reservas desarrolladas, pero aún no se publica el informe anual de reservas de PEMEX. La CNH y PEMEX no publican cifras de reservas desarrolladas y no desarrolladas por campo. 
Maloob fueron de 21, 19 y 12\%, respectivamente, lo cual equivale a una relación conjunta de reservas a producción de 6.7 años. Las reservas están concentradas en Maloob, donde reside un poco más del $61 \%$ del total de KMz. En este campo, dicha relación es de 8.2, mientras que la de $\mathrm{Ku}$ es de sólo 4.7 años. La producción acumulada de estos tres campos es cercana al $67 \%$ de las reservas probadas originales. La administración de estos yacimientos es absolutamente crítica y PEMEX no puede caer en la tentación de sobreexplotarlos para mantener la producción, particularmente después de la experiencia de Akal. La tasa de agotamiento es mayor, si se le restan las reservas remanentes no desarrolladas, un mejor indicador de la producción a corto plazo, cuando se enfrentan restricciones de inversión en materia de desarrollo.

Pemex descubrió un conjunto de campos de crudo extrapesado, cerca de kmz y Abkatún-Pol-Chuc. Sus reservas 2P de petróleo crudo ascendieron, al término de 2017, a 2088 millones de barriles. Entre ellos, destaca Ayatsil, un campo gigante descubierto en 2008, que se localiza a unos 130 kilómetros al noroeste de Ciudad del Carmen, en aguas someras entre 125 y 155 metros de profundidad. Inició producción en febrero de 2015 y alcanzó un nivel de tan sólo 38 mbd en junio de 2017. Esta expansión inicial fue limitada por diversas restricciones técnicas y económicas. Otros campos de este grupo como Tekel, Pit y Kayab son de tamaño significativo y los demás son mucho más pequeños (véase cuadro 8). En torno a ellos, se ha instalado una importante infraestructura, por ahora subutilizada, dada la falta de inversiones complementarias.

La extracción de los crudos de estos campos plantea múltiples problemas. En primer lugar, los factores de recuperación supuestos son particularmente bajos y una variación de un punto porcentual tiene un fuerte impacto sobre la producción. Segundo, va a ser necesario diluir su producción con crudo ligero, pues si bien el crudo fluye por su elevada temperatura al aflorar del yacimiento, su manipulación es particularmente difícil. Tercero, el contenido de ácido sulfhí- 
drico $\left(\mathrm{H}_{2} \mathrm{~S}\right)$ de estos crudos es alto, puesto que puede llegar a alcanzar el $21 \%$ mol de $\mathrm{H}_{2} \mathrm{~S}$, por lo que manipularlo es riesgoso y requiere una infraestructura segregada con aceros de alta especificación. Por estos motivos, el desarrollo conjunto de estos campos puede suponer un mayor costo. Cuarto, el tratamiento, estabilización, dilución, mezclado, almacenamiento y descarga del crudo producido deben llevarse a cabo cerca de los pozos, por lo que se necesita contar con un barco cautivo (FPSO) de grandes dimensiones, en que se realicen estas actividades. Quinto, estos crudos no puedan comerciarse antes de ser diluidos y, dadas sus características físicas, su valuación no es sencilla.

\section{Cuadro 8}

Reservas de crudo extrapesado en campos seleccionados de aguas someras hacia finales del 2017"

(millones de barriles)

\begin{tabular}{lrr}
\hline & $2 P$ & ${ }^{\circ} A P I$ \\
\hline Total & 2088 & \\
Ayatsil* & 1042 & 11 \\
Tekel* $^{*}$ & 198 & 11 \\
Utsil* & 143 & 10 \\
Kayab & 226 & 9 \\
Pit & 308 & 11 \\
Baksha & 42 & 10 \\
Pohp & - & 11 \\
Tson & 24 & 8 \\
Kastelan** & - & 10 \\
Kach** & 65 & 10 \\
Alak** & 40 & 10 \\
\hline
\end{tabular}

* Asignado a PEMEX.

** Pertenece al activo Abkatún, Pol, Chuk. El resto de los campos están en el activo KMz.

Fuente: CNH, "Reservas por asignación”, 2017, en https://portal.cnih. cnh.gob.mx/estadisticas.php. 
Pemex se propone licitar un proyecto, bajo la modalidad de farmout (forma de asociación), denominado Ayín-Batsil, que se encuentra en aguas someras del litoral de Tabasco, a unos 50 kilómetros de la costa frente a Frontera. El principal socio privado de esta coinversión será el operador. La convocatoria correspondiente se publicó en marzo de 2017 y la presentación y apertura de las propuestas se realizaron el 6 de octubre, cuando la licitación se declaró desierta. El área contractual cubre 1096 kilómetros cuadrados y se encuentra cerca de infraestructura e instalaciones de PEMEX. Por ahora, incluye cuatro campos no desarrollados y tres prospectos exploratorios en un área en que la empresa estatal perforó diez pozos, el primero en 1988 y el más reciente en 2015. Siete de éstos son de más de 6 mil metros de profundidad. Las pruebas de estos campos produjeron crudos extrapesados, con muy bajo contenido de gas asociado. ${ }^{32}$ La extracción y manejo del crudo plantean problemas técnicos complejos, por lo que PEMEX decidió posponer su desarrollo. El volumen de reservas 2P es de 182 millones de barriles (véase cuadro 9), aunque sobresale el campo Ayín. Será necesario desarrollar un intenso trabajo de perforación para delinear mejor estos campos y así probar reservas adicionales a partir de las actuales estimaciones de reservas $2 \mathrm{P}$ y $3 \mathrm{P}$.

Pemex no ha identificado y dado a conocer proyectos e inversiones específicas que permitan modificar la trayectoria a la baja de la producción de petróleo crudo pesado en 2018. ${ }^{33}$ Tampoco cuenta con una perspectiva que permita determi-

32 G. Hernández, “Ayín-Batsil”, en PEMEx Farmout Day, Houston, julio de 2017, en https://www.pemex.com/Documents/2017pemexfarmoutd ay/5a.GustavoHernández - Offshore Farmout - Ayín Batsil.pdf.

${ }^{33}$ El Plan de Negocios de PEMEx, 2017-2021 (https://www.pemex. com/acerca/plan-de-negocios/Documents/plannegocios-pmx_2017-202 1.pdf), proyecta una producción total de crudo de 1.9 mmbd en 2017 y 2.2 mbd en 2021, cifra inferior a la producción registrada en 2015. El proyecto de presupuesto de 2018 considera una producción ligeramente inferior a 2 mmbd. La información publicada no desagrega la producción de crudo pesado. 
nar las posibles fuentes de su crecimiento en los primeros años de la próxima década. Pronosticar la disponibilidad de crudo pesado para exportación es una tarea aún más difícil, pues dependerá también del volumen y la mezcla de crudos procesados por las refinerías del país. Según aumente la utilización -particularmente baja- de la capacidad de coquización en las refinerías de Cadereyta, Ciudad Madero y Minatitlán, se procesará una mayor cantidad de crudo pesado. La entrada en operación de la planta coquizadora que se construye en Tula -programada para 2019, pero retrasada no poco- también reducirá el excedente exportable de crudo pesado. El diseño de la reconfiguración de las refinerías de Salamanca y Salina Cruz deberá tomar en cuenta la disponibilidad de crudo pesado a partir de 2022-2025, así como la demanda externa de este tipo de crudos. Por ahora, sólo se vislumbra para los años veinte la aportación adicional a la oferta interna de crudo que harían campos de crudo pesado y extrapesado en aguas someras.

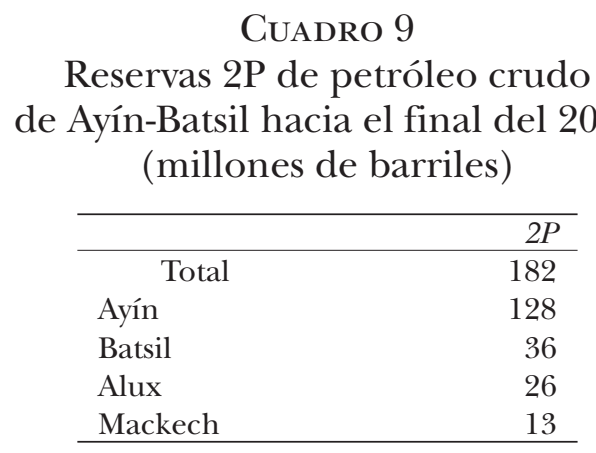

Fuente: CNH, "Reservas por asignación”, 2018, en http://portal.cnih. cnh.gob.mx/estadisticas.php.

Las refinerías mexicanas han estado sujetas a un largo proceso de deterioro que ha visto una caída sustancial en la utilización de la capacidad instalada de sus plantas y de la producción de combustibles terminados, en particular, de com- 
bustibles automotrices. En los últimos veinticinco años, PEMEX y sus asesores externos realizaron diagnósticos detallados de estas refinerías e identificaron las mejoras operativas requeridas para lograr un desempeño más eficiente. $\mathrm{Su}$ instrumentación ha enfrentado obstáculos que no han sido superados, los cuales se refieren a prácticas restrictivas impuestas por la gerencia media y el sindicato de trabajadores, así como recursos presupuestales insuficientes. La carga de crudo pesado del sistema de refinación disminuyó a partir de 2012, si bien su participación en la mezcla de estos crudos se ha sostenido en torno al $43 \% .{ }^{34}$ Bajo la actual configuración de las refinerías, el volumen de crudo pesado podría elevarse un $25 \%$ sobre el volumen de 2017 y aumentar más en la medida en que se dote de unidades de conversión profunda a las refinerías que aún no han sido reconfiguradas. Mientras esto sucede, convendría hacer más ligera la carga de estas refinerías para obtener más productos destilados y reducir la elaboración de combustóleo, particularmente en las refinerías tierra adentro sin capacidad de coquización. La conversión a gas natural del sistema eléctrico va a arrojar un excedente creciente de combustóleo de muy alto azufre, que tiene que exportarse a precios particularmente bajos en la puerta de las refinerías. PEMEx puede suministrar mayores volúmenes de Olmeca e Istmo a estas refinerías e importar crudos extraligeros de Estados Unidos. Para hacerlo, es posible que tenga que resolver previamente problemas de transporte de crudo a las refinerías y rediseñar torres de destilación primaria. ${ }^{35}$

${ }^{34}$ En 2013 las refinerías de PEMEx procesaron 50\% más crudo pesado que en 2017.

35 A. Lajous, "US Crude Oil Exchanges with Mexico", Center on Global Energy Policy, Columbia University, febrero de 2015, en https:/ / energypolicy.columbia.edu/publications/report/us-crude-oil-exchanges-mexico. 
Las fórmulas utilizadas por PEMEx desde 1986, ${ }^{36}$ que fijan los precios mensuales de exportación del petróleo crudo, exigen una revisión de fondo. Desde que fueron diseñadas, se consideró que su aplicación y los resultados que arrojaran deberían ser evaluados periódicamente por un tercero independiente, algo que no se ha dado hasta la fecha. En estos treinta años, se presentaron importantes cambios estructurales en los mercados internacionales de crudo y en la composición de los crudos marcadores y de combustóleo que se comercian en el mercado spot ( precio ocasional, pago y entrega inmediatos); la estructura de precios relativos ha registrado fluctuaciones sorprendentes, que incluso han modificado su signo; la dirección dominante de los flujos de crudo se ha desplazado de la cuenca del Atlántico a mercados asiáticos; los estrangulamientos en los sistemas de transporte, no menos que su posible resolución, han provocado cambios fundamentales de precio entre crudos, como el WTI -que se intercambia tierra adentro en Cushing, Oklahoma, donde se taza-, el West Texas Sour (wTs) -cuyo precio se fija en Midland, Texas- y crudos con mayor liquidez, que se comercializan en la costa del Golfo -como el Mars, el LLS y el Brent-; han surgido nuevas corrientes de crudo en mercados específicos que intensifican la competencia; y la estructura de refinación cuenta hoy con una mayor capacidad de conversión profunda, que aumenta la demanda relativa de crudos pesados.

Las fórmulas buscaron simular la formación de precios de mercado. Se recurrió a ellas dadas las diferencias de calidad, así como de términos y condiciones contractuales de

${ }^{36}$ A. Lajous, "Crude Oil Pricing Formulas. A Personal Commentary", Oxford Energy Forum, noviembre de 2006, en https://www.oxfordenergy. org/wpcms/wp-content/uploads/2011/02/OEF-67.pdf. 
venta, respecto a los principales crudos marcadores. Las fórmulas construían un crudo sintético al que podían vincularse los crudos mexicanos, ante la falta de sucedáneos cercanos cotizados en el mercado spot. En aquel entonces, una ventaja importante para PEMEx era que las fórmulas eliminaban la discrecionalidad de sus ejecutivos en la formación del precio. Además, dadas las restricciones de personal con experiencia en la comercialización de petróleo crudo, este mecanismo podía manejarse con un equipo pequeño de ejecutivos. A su vez, las fórmulas ofrecían a los clientes de PMI la posibilidad de cubrir riesgos de precios.

Conviene centrar inicialmente el análisis en la determinación de los precios regionales del Maya, el principal crudo de exportación de México. Los otros crudos de exportación siguen pautas similares en la formación de sus precios. PMI fija el precio de sus principales crudos de exportación mediante fórmulas que relacionan los precios del Olmeca, el Istmo y el Maya a precios de referencia de crudos seleccionados y de combustóleo en el mercado spot. Estas fórmulas se ajustan mensualmente mediante variaciones en una constante (denominada $K$ ), según las condiciones que imperan en el mercado. Ocasionalmente se modifica la estructura de las fórmulas o las referencias internacionales a las que se vinculan los precios de sus crudos. PMI aplica fórmulas diferentes para cada uno de los tres mercados -América, Europa y Asia- en que participa. Aplica también diferentes constantes para subregiones específicas. Utiliza, así, la misma fórmula para la costa del Golfo y la costa occidental de Estados Unidos, pero con diferentes valores de la constante. Los precios de los crudos mexicanos se expresan en términos de libre a bordo (FOB, en inglés), lo que permite comparar los precios en puerto mexicano del mismo crudo en cada uno de sus mercados.

Las que siguen son las fórmulas actuales del Maya:

Golfo

$P=0.40($ WTS + USGC HSFO $)+0.10$ LLS +0.10 Brent $($ dated) $+K$ 
Europa

$P=0.527$ Brent (dated) +0.467 Fo No. $63.5 \% S-($ Fo No. $61 \% S$-FO No.6 $3.5 \% S)+K$

Asia

$P=($ Oman + Dubai $) / 2+K$

Los principales términos de estas fórmulas son: West Texas Sour (wTS); Light Louisiana Sour (LLS); Brent con fecha firme de entrega (Brent dated); combustóleo de alto azufre en la costa estadounidense del Golfo (USGC HSFO); combustóleo de alto y bajo azufre (Fo No. 6 de 3.5 y $1 \%$ de azufre); y la constante de ajuste $(K)$.

Hay dos crudos pesados mexicanos que no cuentan con sus propias fórmulas (o éstas no se publican), el Altamira y el Talám. Es de suponer que sus precios se descuentan con respecto del Maya y que su diferencial varía según las condiciones del mercado. El primero de éstos tiene como destino el Golfo, donde se utiliza para la formulación de asfalto, y el segundo fluye preferentemente al Lejano Oriente, si bien se realizaron en 2015 algunas transacciones de Talám en Estados Unidos. Las fórmulas del Olmeca y del Istmo tienen una estructura similar, pero difieren en cuanto a sus referencias y a los ponderadores utilizados. ${ }^{37}$

En términos generales, el tamaño y la volatilidad mensual de la constante $K$ de las fórmulas es un indicador de su

${ }^{37}$ Las fórmulas de precios, así como las referencias de precios, son publicadas por PMI en "Fórmulas de los Crudos Mexicanos de Exportación", en https://www.pmi.com.mx/Documents/FormulasCrudos.pdf. Sin embargo, no aparecen en esta publicación las fórmulas para el Altamira y el Talám, ni incorpora cambios recientes en las referencias del combustóleo de las fórmulas para las Américas. Véase A. KALt, "It Ain’t Heavy It's My Maya - Impact of Changes to the Mexican Heavy Crude Benchmark", RBN Energy, 11 de enero de 2017, en https://rbnenergy.com/itaint-heavy-its-my-maya-impact-of-changes-to-the-mexican-heavy-crudebenchmark, y su segunda parte, "It Ain't Heavy It's My Maya - Impact of Changes to the Mexican Heavy Crude Benchmark - Part 2", RBNEnergy, 26 de enero de 2017, en https://rbnenergy.com/it-aint-heavy-its-my-mayaimpact-of-changes-to-the-mexican-heavy-crude-benchmark-part-2. 
operación y ajuste. Niveles y variaciones elevadas de ésta señalan que los precios de referencia y su ponderación no reflejan adecuadamente el valor del crudo preciado. En el pasado, las constantes del Maya eran de menor dimensión y sus variaciones mensuales eran relativamente pequeñas. Éste no es el caso actualmente. Por ejemplo, en 2016 el valor de la constante en Asia equivalió, en promedio, al $30 \%$ del precio, mientras que en Europa la constante empleada determinó el $13 \%$ del precio y en la costa del Golfo el $6 \%$. El promedio de las variaciones mensuales de la constante fue relativamente elevado en las tres regiones. Así, los precios fuera del mercado del Golfo fueron más bajos, sujetos a mayores fluctuaciones y determinados en mayor medida por factores discrecionales.

\section{Precios Regionales de CRUdos mexicanos Y COSTOS DE DIVERSIFICACIÓN}

Las fluctuaciones de los diferenciales de precios entre el Brent y el WTI ${ }^{38}$ durante la presente década determinaron no poco el comportamiento de los precios de los crudos mexicanos y su estructura regional. Descuellan dos inflexiones en los precios relativos de estos crudos marcadores. La primera, en 2008, y la segunda, al inicio del segundo semestre de 2014. Se observa también la variación de los diferenciales de precios de estos crudos respecto al de otros que se comercian ampliamente, como es el caso de los mexicanos. Estas inflexiones son cruciales para comprender el origen, la evolución y las consecuencias de la diversificación geográfica de las exportaciones mexicanas. Los precios del crudo que se determinan en el oeste de Texas y en Oklahoma han sido afectados recurrentemente por la falta de capacidad de transporte que obstaculizó su flujo eficiente y suficiente hasta la costa del Golfo, donde compiten con precios internacionales del crudo. Este

${ }^{38} \mathrm{El}$ precio del wTI determina, a su vez, el del wTs. 
orden de cosas ha supuesto, en momentos críticos, grandes descuentos del wTI y wTs respecto al precio del Brent.

\section{GrÁfICA 3}

Diferencial mensual de precios spot de los crudos Brent y wTI entre 1990 y agosto de 2018 (dólares por barril)

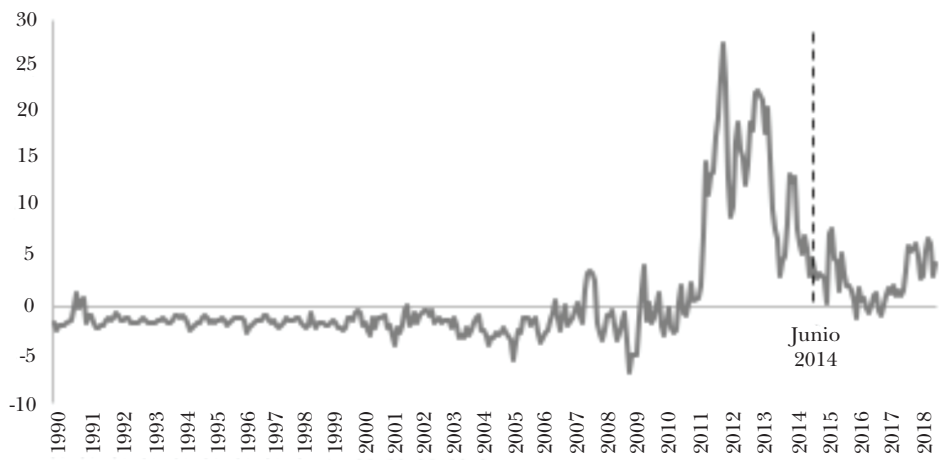

Fuente: EIA, "Petroleum and Other Liquids, Spot Prices", en https:// www.eia.gov/petroleum/data.php.

Entre 1990 y 2009, la brecha de precios del Brent y el wTI se estabilizó en torno a una media de 1.40 dólares por barril a favor del wTI. Esta relación se invirtió en 2010 y alcanzó un diferencial promedio sin precedente en 2012 de 17.58 dólares por barril a favor del Brent. Esta diferencia cayó abruptamente en la segunda mitad de 2014, al disminuir a 41 centavos por barril en 2016. La EIA pronosticó en agosto de 2017 que dicho diferencial aumentaría en 2017 y 2018, lo que ha sucedido. ${ }^{39}$ Después de un largo periodo de estabilidad, el comportamiento errático de este diferencial afectó directamente a los precios regionales de los crudos mexicanos. En el perio-

39 U.S. Energy Information Administration, "Short-Term Energy Outlook". 
do que va de 2011 al primer semestre de 2014, éstos alentaron el envío de petróleo crudo a Europa y el Lejano Oriente. Sin embargo, a partir de julio 2014 -un plazo que se acerca a los 4 años-, este estímulo resultó insuficiente para justificar económicamente la diversificación en mercados diferentes al de Estados Unidos.

El entusiasmo de los directivos de PMI por la diversificación en Asia no parece haber considerado este cambio fundamental de las condiciones del mercado. Por motivos difíciles de comprender, PMI no fue capaz de ajustarse al nuevo entorno a pesar de señales de precios claras y vigorosas. En la segunda mitad de 2017, el diferencial Brent/WTI se amplió nuevamente por las restricciones de transporte de Cushing, la cuenca de Permian y el sureste de Texas a la costa del Golfo, así como los mayores costos de transportar el crudo de esta área a Asia en lugar de Europa. En diciembre de ese año, las disrupciones del sistema de oleoductos Forties en el Mar del Norte ampliaron también el diferencial de precios (véase supra gráfica 3).

\section{Cuadro 10}

Diferencia de precios de exportación Fob de crudo Maya con destino europeo y asiático respecto al entregado en América entre 2012 y 2018, según PMI (dólares por barril)

\begin{tabular}{lccc}
\hline & América & Europa & Asia \\
\hline 2012 & - & +1.14 & +1.82 \\
2013 & - & +1.04 & +0.07 \\
2014 I & - & -1.60 & +2.54 \\
2014 II & - & -19.75 & -14.48 \\
2015 & - & -7.68 & -7.38 \\
2016 & - & -3.18 & -1.66 \\
2017 I & - & -2.39 & -2.90 \\
2017 II & - & -1.62 & -0.76 \\
2018 I & - & -2.71 & -0.67 \\
\hline
\end{tabular}

Nota: I (primer semestre); II (segundo semestre).

Fuente: base de datos institucional de PEMEX. 
El precio promedio del Maya, cuya estructura de precios regionales durante los últimos tres años (julio de 2014-junio de 2017) figura en el cuadro 10, fue sistemáticamente superior en América, si bien la diferencia disminuyó a partir de niveles excepcionalmente altos. Recientemente los diferenciales regionales del Maya se han ampliado nuevamente, al igual que los del Istmo y el Olmeca. En cuanto al Maya, de los 36 meses considerados, en tan sólo unos pocos el precio en el Lejano Oriente fue ligeramente superior al de las Américas. Por lo que toca al Istmo y el Olmeca, fueron un par de meses cada uno, hasta que desaparecieron del mercado. Todo lo cual ocurrió a pesar de la ampliación del diferencial entre el Brent y el wTI.

Los precios de los crudos mexicanos que tienen a América por destino están parcialmente referenciados a los precios del WTS, mientras que los que van a Europa se vinculan directamente a los precios del Brent. Las referencias utilizadas para el crudo colocado en Asia se derivan de manera indirecta del Brent. Así, la magnitud de la brecha de precios entre el wTs (y necesariamente el wTI) y el Brent determinan, en gran medida, las ventajas relativas de exportar crudo mexicano a Estados Unidos, frente a otros mercados. Esta brecha creció notablemente hasta mediados de 2014, alentando el envío de crudo a Europa y Asia. Sin embargo, a partir de julio de ese año, el diferencial de precios cayó significativamente, haciendo más atractiva la venta de crudo en Estados Unidos. La inclusión del wTs en las fórmulas de crudo mexicano para América representa un problema adicional. Se trata de un crudo cuyo precio refleja condiciones de mercado tierra adentro y no las que privan en la costa del Golfo. Además, sus volúmenes comercializados en el mercado spot son limitados. Por ambas razones no constituye hoy en día una buena referencia para la formación de precios de los crudos mexicanos. ${ }^{40}$

40 "New Fuel Oil Spec Adds Uncertainty to Maya Price", Argus, en https:/ / www.argusmedia.com/pages/NewsBody.aspx?id=1369682\& menu=yes; "The US Gulf Coast High Sulfur Fuel Oil Price: Oil Price As- 
Las restricciones ambientales de usar combustóleo de alto azufre (HSFO) en el transporte marítimo acordadas por la Organización Marítima Internacional, y las especificaciones más exigentes que se introducirán en enero de 2020, bajarán el precio relativo del HSFO. Estas regulaciones pretenden reducir las emisiones a la atmósfera de óxidos de azufre $\left(\mathrm{SO}_{\mathrm{X}}\right)$ de embarcaciones, obligando a usar combustóleo de $1 \%$ de azufre (LSFO), dísel marino (MGO) y con el tiempo gas natural licuado. Los menores precios del HSFO, que tendría que diluirse con otras corrientes de las refinerías, castigarán los resultados de las que lo producen, así como los precios de los crudos indexados al precio del combustóleo. ${ }^{41}$ Las refinerías no reconfiguradas de Tula, Salamanca y Salina Cruz verán sus resultados particularmente afectados.

Más importante aún será la incidencia de menores precios relativos del combustóleo sobre la formación del precio de exportación del Maya destinado a América y Europa y, en menor medida, sobre el del Istmo que se vende en Europa. Las fórmulas de precios del Maya comercializado en América aplican un ponderador de $40 \%$ al HSFO y en la que se utiliza para Europa este ponderador es aún mayor. En el caso del Istmo en Europa, el ponderador del combustóleo es superior al $11 \%$. Es muy probable que estas fórmulas tengan que modificarse. En enero de 2017, PMI cambió la referencia de precios del combustóleo, al remplazar la cotización del Gulf Coast No. 6 Fuel Oil de 3\% S con la del RMG 380 3.5\% S, un combustible marino. Estos dos combustibles son similares. Si bien el RMG 380 es más tolerante con respecto de la especificación de azufre, es más restrictivo respecto a otras especificaciones que elevan el costo de producir este combustible, lo

sessments", SEFP Global Platts, en https:/ / www.platts.com/price-assessmen ts /oil/usgc-fuel-oil.

41 A. HalfF, "Slow Streaming to 2020: Innovation and Inertia in Marine Transport and Fuels", Center on Global Energy Policy, Columbia University, 10 de agosto de 2017, en https:/ / energypolicy.columbia.edu/ sites/default/files/energy/SlowSteamingto2020InnovationandInertiainMarineTransportandFuels817.pdf. 
cual obligó a PMI a modificar con fines compensatorios la constante de la fórmula del Maya, quizá por arriba del descuento recomendado por Platts, la empresa que publica las valuaciones de ambos combustibles. ${ }^{42}$

México es hoy el principal proveedor individual de petróleo de España. Las exportaciones mexicanas a ese país aumentaron consistentemente a partir de 2010, al alcanzar un nivel de 178 mbd en 2016, monto que se incrementó ligeramente en 2017 y que representa el 15\% de las importaciones totales de dicho país. ${ }^{43}$ Predominan las ventas de crudo pesado y el cliente preponderante es REPSOL. Las fórmulas de precios utilizadas necesitan una recalibración rigurosa. Es interesante constatar que las exportaciones mexicanas a ese país no fueron afectadas por los conflictos de carácter corporativo suscitados por PEMEX y SACYR Vallehermoso en el seno de REPSOL entre 2011 y 2014. Esta empresa y CEPSA continuaron comprando volúmenes crecientes de crudo Maya, dado un precio particularmente atractivo, la configuración de sus refinerías y su larga experiencia procesando este crudo. Una buena parte del volumen que fue desplazado de Estados Unidos tuvo como destino España, hacia donde se dirigió en 2016 el 19\% de las exportaciones mexicanas de crudo. ${ }^{44}$

Las fórmulas de precios del crudo enviado a Asia son particularmente sencillas. Lo que en realidad especifican es que PEMEX otorgará un descuento variable respecto al promedio de precios de los crudos Omán y Dubai, mediante modificaciones de la constante $K$. La utilización de estos precios de referencia está siendo revisada por los principales productores de la región. Los precios actuales del Maya tienen un amplio componente discrecional, algo que se había querido evitar. Toda vez que las ventas a Asia eran poco importantes, esta situación era incómoda, pero manejable. Hoy en día, en

42 Kalt, arts. cits.

43 Cores, "España: importaciones de crudo por áreas geográficas y países, 1996-2017”, en https://www.cores.es/es/estadisticas.

${ }^{44}$ U.S. Securities and Exchange Commission, informe citado, p. 88. 
que una proporción importante del crudo fluye a esa región, el mecanismo empleado es cuestionable. Destacan los descuentos otorgados al Maya, cuando se ampliaron las ventas al Lejano Oriente en 2014 y 2015 (véase cuadro 10).

En Asia, se otorgaron descuentos excepcionalmente amplios a los precios del Talám, un crudo que es parte de la mezcla de Maya. Bajo condiciones de oferta excedente de crudo extraligero, es posible que un crudo extrapesado como el Talám sea útil para hacer más pesada la carga de refinación, sin reducir la proporción de crudo extraligero necesaria. Al igual que los crudos canadienses más pesados que el wcs, esta ventaja mejora su competitividad. Hasta ahora, el destino preferido del Talám ha sido Asia, con la noción equivocada de que al aislarlo en ese mercado, no se contaminaría el proceso de formación de precios del Maya en Estados Unidos. Es posible que precios que reflejaran su valor de mercado en el Golfo supondría menores descuentos que los otorgados en Asia, donde no se enfrenta ni una sobreoferta similar de crudos extraligeros ni se cuenta con una amplia capacidad de coquización.

En 2016, el descuento otorgado al Talám fue considerable. Éste se integró del diferencial del Talám respecto al Maya vendido en Asia (5.98 dólares por barril) y el del Maya en esa región frente al que rigió en las Estados Unidos (1.70 dólares por barril), cuya suma equivalió al 21\% del precio del Maya que privó en la costa del Golfo. ${ }^{45}$ En 2015, el Talám llegó a representar el $10 \%$ de las exportaciones totales de crudo pesado. Debe también tomarse en cuenta que en ese año, el 37\% de las exportaciones de Talám tuvo como destino la costa del Golfo. La magnitud del descuento y una menor disponibilidad del Talám podrían explicar la disminución del volumen exportado de este tipo de crudo en 2016. El surgimiento y posible reducción volumétrica del Talám podrían también indicar que la segregación de esta corriente del Maya se debió, más que a nada, a problemas temporales

${ }^{45}$ Ibid., p. 87. 
de infraestructura ocasionados por la explosión de la plataforma Abkatún Permanente en abril de 2015 y su lenta rehabilitación.

Un ejercicio contrafactual simple permite dimensionar el costo que tuvo la diversificación. El supuesto básico del ejercicio es que los precios en el Golfo no habrían sido afectados, si PMI hubiera intentado mantener su participación de mercado. Para estos efectos, se comparan los ingresos que efectivamente fueron recibidos por las ventas de los tres crudos con los que se hubieran obtenido, si su participación regional hubiera permanecido constante durante el periodo según los niveles realizados en el segundo semestre de 2014. Los ingresos totales derivados de la exportación hubieran sido aproximadamente 200 millones de dólares superiores, si se hubiera congelado el proceso de diversificación al inicio de este periodo a mediados de 2017 , cuando el $60 \%$ de este monto es atribuible al Maya. El desplazamiento regional de crudos no hubiera sido muy grande. En promedio, se hubieran mantenido en Estados Unidos aproximadamente $85 \mathrm{mbd}$ adicionales de Maya en los tres años, 60 mbd de Istmo y $10 \mathrm{mbd}$ de Olmeca. La pregunta central es cuánto habrían caído los precios en América, si PMI hubiera retenido dichos volúmenes en este mercado. Esta cuestión sólo puede responderse con base en una estimación de la curva de demanda de crudo pesado en la costa del Golfo y más específicamente de la elasticidad-precio de la demanda en el intervalo volumétrico relevante. PMi cuenta con estas herramientas. Sería interesante reproducir este ejercicio con base en los instrumentos que tiene la empresa.

Es posible que PMI explique que se vio obligado a diversificar sus ventas de Maya ante la creciente presión competitiva ejercida por mayores volúmenes de crudo pesado canadiense que llegaba al Golfo y por los descuentos otorgados por Venezuela para garantizar el flujo de sus crudos a ese mercado. Argumentará que tuvo que desplazar crudo para no verse obligado a reducir el precio promedio vigente en la costa del Golfo. En su momento, cuando ampliaba sus 
ventas en Asia, festejó las bondades de la diversificación a mercados en expansión. Nunca explicó que se trataba de una acción defensiva. Otro argumento que podría esgrimirse es que la diferencia entre los precios de los crudos mexicanos en el Golfo y los realizados en otros mercados son el costo de un seguro contra el riesgo político de depender de un solo comprador o de otras ventajas económicas derivadas de un portafolio de clientes geográficamente diverso. No hay, sin embargo, evidencia de que PMI haya visto la diversificación como un instrumento de administración de riesgos y que haya discutido la prima que estaba dispuesta a pagar por ella. En 2014, PMi tardó en aceptar que los cambios en el precio relativo del wTi y el Brent no eran pasajeros. Además, la entonces reciente suscripción de contratos a plazo en Asia le había restado flexibilidad a la colocación del crudo, ante un cambio fundamental de circunstancias.

Lo que en todos estos años poco cambió fueron las fórmulas de precios del crudo mexicano y la estrategia comercial implícita en éstas. Sólo se realizaron ajustes marginales, aunque no siempre consistentes con una estrategia comercial que originalmente fue diseñada para una fase de expansión de las exportaciones y de la introducción de mayores volúmenes de crudo pesado. Hoy, el tema dominante es la contracción de las exportaciones mexicanas en un mundo más volátil, en el que difieren en mayor medida las condiciones específicas de los mercados atendidos por PMI. Convendría recalibrar las fórmulas existentes y explorar otras alternativas de formación de precios según los objetivos centrales de una nueva estrategia de exportación.

Un tema importante que surgirá en un futuro no muy lejano es la relación entre la determinación de precios por productores privados en México y los precios fijados por PMI. El fin del monopolio comercial de PEMEx y de PMI lleva necesariamente a cambios institucionales que tendrán que prepararse cuidadosamente. Una vez iniciada la recuperación de precios y alcanzada una cierta estabilidad, es un buen momento para llevar a cabo una evaluación rigurosa de las fór- 
mulas de fijación de precios del crudo mexicano e incluso del mecanismo mismo de formación de precios de exportación. La liberalización del mercado de productos petrolíferos y el establecimiento de nuevos productores de petróleo crudo en México establecen nuevas condiciones que obligarán a modificar los mecanismos a los que se sujetará el comercio exterior de PEMEx. Sería importante iniciar de inmediato el diseño de una nueva estrategia comercial que sustituya a la actual, la cual manifiesta claros signos de agotamiento. Es probable que las fórmulas tengan que cambiar para adecuarse a la nueva estrategia y a las nuevas condiciones de los mercados de petróleo crudo.

\section{Liderazgo de PRecios del Maya}

Por mucho tiempo, el Maya ha servido de referencia para tazar los crudos pesados que llegan al Golfo. El precio de los crudos venezolanos, así como otros crudos sudamericanos, han seguido muy de cerca al Maya. Asimismo, el precio del crudo canadiense wcs ha buscado igualarse al del Maya puesto en la costa del Golfo. El costo del transporte de Hardisty, Alberta, a Houston tiene un papel clave, pues fluctúa según la capacidad de transporte disponible, pero en todo caso es una fracción importante del precio entregado en la costa del Golfo. Por algún tiempo, los venezolanos simplemente tomaron el precio del Maya y le aplicaron un descuento para fijar el precio de sus principales corrientes de crudo. Usualmente este diferencial varía según las condiciones del mercado, dentro de un intervalo relativamente estrecho de precios. La formación del precio del wcs es un poco más compleja, pues toma en cuenta tanto el costo del diluente que requiere, como el del transporte. Ambos tienden a fluctuar, por lo que los diferenciales entre el Maya y el wcs también lo hacen. Dado el liderazgo ejercido por el precio del Maya hasta ahora, su formación requiere de fórmulas bien calibradas y transparentes que reflejen las condiciones y presiones del mercado. 
Si éste no es el caso, se distorsiona la estructura de precios de crudos pesados que llegan a las refinerías del Golfo.

Mayores volúmenes de crudo pesado, y capacidad adicional de transporte por oleoductos desde Canadá, alentaron el surgimiento de un mercado spot activo de crudo pesado y amargo en la costa del Golfo. No había sido posible crear uno en torno a crudos pesados provenientes de México, Venezuela, Brasil, Colombia y Ecuador, entre otros, pues sus precios son determinados por empresas estatales y sus gobiernos. La evolución del precio del Maya en los últimos años diverge significativamente del valor de mercado de otros crudos pesados. Argus, la empresa de información petrolera, ahora publica su evaluación de precios del wcs. ${ }^{46}$ Conviene subrayar que en 2017 llegaron a la costa del Golfo $381 \mathrm{mbd}$ de crudo pesado canadiense y 558 mbd de crudo Maya, y que esta brecha volumétrica tiende a reducirse con rapidez. En estas condiciones es muy posible que el liderazgo de precios que ha detentado el Maya hasta ahora esté próximo a perderse y que pueda ser sustituido por la valuación del precio spot del wCs en la costa del Golfo, una vez superadas las restricciones al transporte de crudo pesado canadiense. Las crecientes distorsiones producidas por la fórmula del Maya tienen que ser corregidas, si PMI desea preservar su liderazgo de precios.

Este liderazgo, ejercido durante muchos años, no parece haber sido una fuente relevante de valor para PEmex. Más importante fue contar con una cartera de grandes clientes cuyas refinerías consideraban al Maya como parte integral de la carga base de sus plantas de conversión profunda. Los clientes de PMI podían mitigar los riesgos comerciales de su cartera de crudos a partir de una corriente de Maya firmemente anclada en fórmulas públicas de precios, transparentes y bien comportadas. Pemex pronto tendrá la opción de incorporar el precio del was en sus fórmulas de precios. Los

46 "Wcs Houston: A New Price Signal for Heavy Crude at US Gulf Coast", Argus White Paper, 2016, en https://www.argusmedia.com/ /me$\mathrm{dia} /$ files/pdfs/white-paper/argus-wcs-houston-wp.pdf?la=en. 
volúmenes comercializados de este crudo en la costa del Golfo y en Oklahoma son sustanciales y, una vez disipadas las dudas respecto a la liquidez y robustez de este crudo de referencia, PMI podría utilizarlo ventajosamente. Tiene además la posibilidad de comercializarse en pequeños lotes transportados por oleoducto, con lo cual se multiplica el número de transacciones realizadas. Alternativamente, PMI también podría convertir el Maya en crudo marcador, lo cual, sin embargo, haría necesario modificar ciertas cláusulas contractuales para alentar el desarrollo de un mercado secundario de Maya, que requeriría una fuerte disciplina comercial para dar mayor poder discrecional a sus comercializadores.

La expansión de la capacidad de transporte a los mercados del Medio Oeste y, más recientemente al Golfo, redujeron los diferenciales entre el was y el WTI. En 2013, éste promedió 25.20 dólares por barril y en 2015 cayó a 13.52 dólares. A partir de entonces y hasta fines de 2017, se mantuvo relativamente estable, aunque se ha ampliado de nuevo de manera significativa. En octubre de 2018, este diferencial ascendió a 29.61 dólares por barril. Los principales cambios se dieron en el transcurso del colapso y la paulatina recuperación del WTI. Esta brecha no se reflejó de manera similar en lo que toca a los diferenciales del wTI y el Maya y entre el Maya y el wCS (véase cuadro 11). En enero y febrero de 2018, la brecha entre el wCS y el wTi alcanzó nuevamente un nivel de 25 dólares por barril. La explicación es compleja. En el caso de Canadá, hay ciclos estacionales que reflejan la disponibilidad del crudo, eventos catastróficos, como los recientes incendios en Alberta, la entrada de capacidad adicional de transporte y problemas de calibración de las fórmulas del Maya.

En la primera mitad de 2017, el diferencial de precios entre el Maya FOB en terminales de exportación y el wCS en Hardisty, Alberta, fue de 6.87 dólares por barril (véase cuadro 12). El diferencial respecto al Maya entregado en Houston fue de 7.60 dólares por barril, una cifra ligeramente por arriba de la tarifa de transporte entre Hardisty y Houston. En este periodo, sus precios tendieron a alinearse. PMI fija el pre- 
cio del Maya un poco antes del inicio del mes en cuestión, con base en las fórmulas vigentes. El wcs se ajusta competitivamente al mismo. Cuando el diferencial entre el precio FOB en Hardisty y el CIF (costo, seguro y fletes, en inglés) en Houston es menor a siete dólares por barril, no se logra cubrir el costo regulado de transporte al Golfo. Si es superior a este umbral, la oferta está restringida. Durante el verano de 2017, este diferencial inició su ascenso, el cual se aceleró en el cuarto trimestre. En diciembre, el diferencial entre el Maya y el wCS promedió 11.17 dólares por barril, aunque alcanzó niveles diarios significativamente superiores, una clara señal de restricciones de transporte.

Cuadro 11

Diferenciales de precios del wTI, wCS y Maya entre 2012 y 2017

(dólares por barril)

\begin{tabular}{|c|c|c|c|}
\hline \multicolumn{4}{|c|}{ Diferenciales } \\
\hline & WTI-WCS & WTI-Maya & Maya-WCS \\
\hline 2012 & 21.03 & -5.46 & 26.49 \\
\hline 2013 & 25.20 & -1.15 & 24.05 \\
\hline 2014 & 19.40 & 7.23 & 12.17 \\
\hline 2015 & 13.52 & 5.35 & 8.17 \\
\hline 2016 & 13.84 & 7.12 & 6.72 \\
\hline 2017 & 11.98 & 4.07 & 7.91 \\
\hline $2018^{*}$ & 21.93 & 5.25 & 16.68 \\
\hline
\end{tabular}

* Enero-septiembre.

Fuente: Baytex Energy Corporation, "Historical wcs Pricing", octubre de 2018, en https://www.baytexenergy.com/files/pdf/Operations/ Historical_WCS_Pricing_October_2018.pdf.

El diferencial de precios entre el Maya y el $L L S$ tendió a reducirse por la mayor producción de crudos ligeros en Estados Unidos, respecto a la disponibilidad de crudos pesados, particularmente en el Golfo de México, dada la baja de las exportaciones de México, Venezuela y otros países suda- 
mericanos. Asimismo, cuando los países de la opeP adoptan cuotas de producción, los primeros crudos que se sujetan a un recorte volumétrico son los pesados, cuyos precios son más bajos. La reducción del diferencial entre crudos ligeros y pesados disminuye la rentabilidad de las refinerías complejas, restándoles ventaja competitiva. En la gráfica 4 se observa con claridad la compresión del diferencial entre estos crudos. ${ }^{47}$ A partir de la segunda mitad de 2017, este diferencial se amplió nuevamente por el mal funcionamiento de la fórmula del Maya y por un esfuerzo de ventas errático.

\section{GRÁFICA 4}

Diferenciales mensuales de precios de los crudos wCS, Maya y LLs entre 2015 y julio de 2018 (dólares por barril)

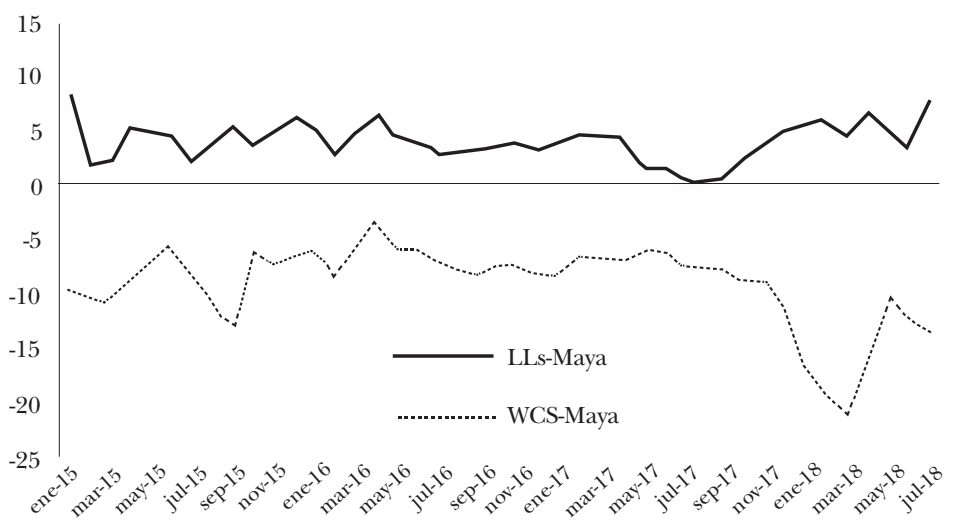

Fuente: PEMEX, EIA y Baytex Energy.

En fechas recientes, dos interrupciones sustanciales de producción en Alberta redujeron el diferencial por abajo del

${ }^{47}$ U.S. Energy Information Administration, "Changing Quality Mix is Affecting Crude Oil Price Differentials and Refining Decisions", 21 de septiembre de 2017, en https://www.eia.gov/todayinenergy/detail.php?id= 33012. 
umbral de 7 dólares: en junio y julio de 2015, por los devastadores incendios en Alberta, y en mayo y junio de 2017, como resultados de la explosión de una planta de Syncrude. En 2015 y 2016, el diferencial de precios entre el wTI y el wCS promedió 13.52 y 13.84, pero en mayo y junio de 2015 descendió temporalmente a 8.54 y 7.44 dólares por barril respectivamente, lo cual cubrió el descuento de calidad, pero sólo una fracción del costo de transporte. Durante estas restricciones puntuales de suministro, se redujo el flujo de crudo canadiense al Golfo, llegando sólo al Medio Oeste. México pudo haber aprovechado estos dos eventos para retomar participación de mercado, pero no hay evidencia de que lo haya intentado. En 2018, las restricciones de transporte del wCS a las que se ha aludido incrementaron de manera sustancial los diferenciales entre el Maya y el wcs.

\section{Cuadro 12}

Precios trimestrales del crudo Maya y el wcs y sus diferenciales entre 2017 y la primera mitad de 2018 (dólares por barril)

\begin{tabular}{lrrrrr}
\hline & \multicolumn{2}{c}{ Maya } & WCS & \multicolumn{2}{c}{ Diferenciales } \\
& FOB & CIF & FOB & CIF $/ F O B$ & FOB \\
\hline 2017 & & & & & \\
I & 44.73 & 45.42 & 37.34 & 8.08 & 7.39 \\
II & 43.55 & 44.33 & 37.16 & 7.17 & 6.39 \\
III & 45.91 & 47.24 & 38.27 & 8.97 & 7.64 \\
IV & 52.99 & 53.93 & 43.14 & 10.79 & 9.85 \\
2018 & & & & & \\
I & 57.63 & 58.14 & 38.59 & 19.55 & 19.04 \\
II & 62.46 & 62.74 & 48.61 & 14.13 & 13.85 \\
julio & 66.31 & 66.92 & 52.84 & 14.08 & 13.74 \\
agosto & 65.47 & nd & 48.54 & nd & 16.93 \\
septiembre & nd & nd & 40.38 & nd & nd \\
\hline
\end{tabular}

Fuente: Baytex Energy Corporation, "Historical wcs Pricing"; base de datos institucional de PEMEx; EIA, "Landed Costs of Imported Crude for Selected Crude Streams", en https://www.eia.gov/dnav/pet/pet_ move_land2_k_m.htm. 


\section{OTROS FACTORES COMERCIALES E INSTITUCIONALES}

Hay muchos más factores de naturaleza propiamente comercial que pueden contribuir a explicar el comportamiento de las exportaciones mexicanas de petróleo crudo, así como la falta de una redefinición estratégica que considere los cambios de circunstancias a los que se ha hecho alusión. Éstos pudieran ser la posible suscripción de acuerdos contractuales a mediano plazo en Asia que redujeron la flexibilidad de PMi. Pueden también haber incidido los descuentos otorgados al Talám sobre las ventas de Maya para promover exportaciones al Lejano Oriente. Prevalecen problemas de calibración de las fórmulas de precios de PEMEx bajo condiciones de alta volatilidad, que se reflejan en la amplitud de las fluctuaciones de la constante $K$ por las fallas estructurales de las fórmulas. Los cambios registrados en crudos marcadores y en las referencias de precios utilizadas han incidido también en la formación de los precios de exportación. Durante la crisis petrolera reciente, las empresas petroleras incurrieron en fallas de análisis de mercados ante las turbulencia e incertidumbre que enfrentaron. PMi no fue la excepción. Sin embargo, da la impresión de que no ha realizado un análisis cuidadoso de sus errores de perspectiva y de estrategia. Es también posible que PMI haya dado mayor prioridad a la importación de productos, por sus importantes repercusiones sobre el mercado interno, que al manejo de las exportaciones de crudo.

Entre los muchos factores que contribuyen a explicar la pérdida de participación de mercado en la costa del Golfo, y la persistente incursión en otros mercados, está la distracción de PMI de sus tareas fundamentales. Esta empresa comercializadora de hidrocarburos no parece haber registrado oportunamente el cambio de circunstancias en los mercados asiáticos y europeos que supuso la inversión de los precios relativos del Brent y el wTI a la que se hizo referencia. PMI siguió desplegando esfuerzos para abrir nuevos mercados y diversificar sus ventas, cuando los precios ya no lo justifica- 
ban. Sus percepciones del mercado parecen haberse congelado antes de julio de 2014, cuando se inició el derrumbe de los precios. Pemex utilizó a PMI, sus recursos financieros y sus recursos humanos, para llevar adelante diversos proyectos al margen de su alcance y misión institucionales. Aprovechó la mayor flexibilidad que otorgaba la estructura regulatoria de PMI para dar la vuelta a restricciones legales y presupuestales a que PEMEX estaba sujeto. Se le pidió que comprara diversos activos en España, evaluara e invirtiera en proyectos de infraestructura y adquiriera plantas de fertilizantes obsoletas, entre muchas otras transacciones de dudoso valor. Un indicador de esta dispersión es el número de empresas que PMI estableció, que sirvieron de vehículo especial para llevar a cabo dichas actividades. ${ }^{48}$ Para financiar algunas de estas transacciones generó utilidades extraordinarias mediante la distorsión de precios de transferencia, con la aquiescencia de PEMEX y de las autoridades. Afortunadamente, la administración de González Anaya inició la reasignación de estas empresas a otras áreas más acordes con sus respectivas responsabilidades. Sin embargo, no va a ser sencillo desmantelar la estructura desordenada que se creó en torno a PMI.

El estado que guarda la balanza comercial de hidrocarburos entre México y Estados Unidos, así como su posible deterioro, obligan a explorar las ventajas estratégicas y comerciales de una vinculación más orgánica entre las exportaciones de crudo y las importaciones de productos petrolíferos. En el pasado, se vinculó de manera selectiva la contratación de exportaciones de Maya a la construcción de

48 Además de sus filiales dedicadas a actividades comerciales y al manejo de activos relacionados con éstas, PMI estableció una serie de vehículos especiales denominada Field Management Resources, Campos Maduros sanma, Pro-Agroindustria, Azufre Industrial Infraestructura y Desarrollo, Cinturón Transocéanico de Gas Natural, Transocéanico Gas LP, Muestrean del Centro, Hijos de J. Barreras, Ducto de Juárez, entre otras. Véase U.S. Securities and Exchange Commission, "Petróleos Mexicanos, Form 6-K Report”, julio de 2017, en https://www.pemex. com/ri/reguladores/Informacion SEC/20170711_6K_2.pdf. 
coquizadoras en refinerías de sus clientes, a fin de ampliar la demanda de crudo pesado y establecer un destino estable para el entonces creciente flujo de Maya. Ahora podrían analizarse las ventajas de integrar la cadena productiva, vinculando la exportación de Maya a la importación de productos mediante contratos a mediano plazo. La estabilidad resultante no sólo protegería al Maya de una mayor competencia, sino que también podría alentar la inversión en infraestructura para el manejo y comercialización de importaciones.

Esta integración se ha venido dando en la práctica sin necesariamente dar mayor solidez a la relación entre las partes. Un buen ejemplo son los flujos de crudo a las refinerías de Port Arthur y Texas City de Valero y los volúmenes de importación de productos petrolíferos a México originados en estas mismas refinerías (véase cuadro 4). Valero es uno de los principales importadores individuales de crudo Maya y el principal exportador de productos a México. El caso de la coinversión de Shell y PEMEX en Deer Park podría ofrecer una plataforma aún más sólida a la vinculación de flujos de hidrocarburos en ambas direcciones. Estas oportunidades están también condicionadas a la forma como el mercado de productos reaccione ante la disminución del poder monopólico de PEMEx y a la reorganización de PMI, al perder su propio monopolio comercial.

Uno de los grandes retos que enfrenta PMI es la pérdida adicional de participación en el mercado de crudo del Golfo. El aumento de crudo canadiense puede erosionar aún más dicha participación, de no tomarse las medidas pertinentes. De igual manera, el aumento de las exportaciones de Iraq podría también hacerlo. El riesgo principal es la agudización de la competencia en este mercado y la consiguiente presión a la baja del precio de crudos pesados. Los arquitectos de la diversificación geográfica debieron estar conscientes de las dificultades que entraña recuperar ventas en un mercado que fue abandonado a la competencia. Ahora va a ser necesario montar un esfuerzo sostenido que calibre con todo cuidado la oportunidad de acciones tendientes a reto- 
mar la participación de mercado perdida. La pieza más débil del entorno competitivo parece ser Venezuela. Su creciente crisis económica y financiera puede incidir sobre la producción de crudo, al igual que una posible discontinuidad constitucional y la imposición de sanciones adicionales por parte del gobierno de Estados Unidos. La pérdida de producción abriría la posibilidad de una restructuración más tersa del mercado de crudos pesados en el Golfo. Si PEMEx no actúa, otros lo harán. Sin embargo, PMI necesita articular una estrategia de más largo plazo que trascienda oportunidades coyunturales. Tendrá que precisar objetivos, fortalecer su análisis y práctica comercial y crear nuevos instrumentos que le permitan avanzar estratégicamente y maximizar el valor de las exportaciones petroleras. Va a tener que hacerlo en momentos en los que el mercado interno de hidrocarburos estará sujeto a cambios fundamentales. El abandono del monopolio comercial e industrial de PEMEx hará necesario que PMI adquiera un nuevo papel y nuevas formas de operación frente a la competencia.

La estrategia de diversificación de las exportaciones de crudo y su ejecución revelan fallas institucionales que trascienden a PMI y que se refieren a su gobierno. En relación con esta iniciativa específica, no hay claridad sobre la naturaleza y efectividad de los mecanismos de supervisión y autorización a los que se sujetaron las actividades de exportación de petróleo crudo de PMI. ¿Quién vigiló en la práctica la maximización de los ingresos de PMI, de PEMEX y del fisco durante los últimos cuatro años? ¿Sobre qué instancia recae esta responsabilidad hoy en día? ¿El consejo de administración de PMI, el de PEMEX, algún comité intersecretarial, el Sistema de Administración Tributaria, el Fondo Mexicano del Petróleo?

Ha habido una pérdida de transparencia con respecto de las actividades de comercio exterior de PEMEx. La divulgación oportuna de información sobre flujos del comercio exterior de hidrocarburos se ha restringido y han dejado de publicarse series mensuales de transacciones relevantes. Por ejemplo, PEMEx ya no publica los precios y volúmenes men- 
suales de la exportación de petróleo crudo por país de destino, y el Sistema de Información Energética (SIE) de SENER no publica precios de exportación del crudo y productos derivados. ${ }^{49}$ Tampoco se publican cifras mensuales sobre el volumen y precio del Talám y PMI no ha dado a conocer las fórmulas de precios de este crudo y del Altamira. El valor de la constante de las fórmulas de precios sólo se publica para los últimos dos meses y no una serie estadística que permita observar su evolución. En materia de productos la información estadística es aún más restrictiva. Una supuesta confidencialidad comercial limita la disponibilidad de la información y su discusión pública por funcionarios de PMI. Un buen contraejemplo de transparencia es el que ofrece la EIA de Estados Unidos en lo que se refiere a sus transacciones internacionales. Pueden consultarse, en un ambiente amigable al usuario, cargamento por cargamento, su origen y destino, las principales características técnicas de cada cargamento, la refinería donde se procesa cada uno y mucha información más. Las autoridades de Japón, Corea y España publican también información detallada sobre sus importaciones de petróleo crudo y productos petrolíferos. Ahora que se liberaliza el sector petrolero mexicano urge hacer una revisión a fondo de la política de transparencia y de las obligaciones de divulgación relativas a las transacciones internacionales de petróleo crudo, productos petrolíferos y gas natural, como parte del proceso de construcción de mercados y de introducción de la competencia.

\section{CONCLUSIONES Y RECOMENDACIONES}

En los próximos tres años, cuando menos, la producción y exportación de petróleo crudo de México continuarán a la baja. La discusión se centra hoy en torno al ritmo en que

${ }^{49}$ Véase SENER, "Sistema de Información Energética”, en https://sie. energia.gob. $\mathrm{mx} /$ bdiController.do?action=temas. 
ocurrirá. En estas condiciones, PEMEX necesita fortalecer urgentemente sus mecanismos de programación y planeación de las exportaciones a fin de mejorar su capacidad para prever la disponibilidad de excedentes exportables de crudo y sus requerimientos de importación, lo cual supone que PEMEX necesita reoptimizar la segregación económica y técnica de corrientes de producción de petróleo crudo, garantizar un mejor control de calidad y robustecer los mecanismos de optimización conjunta y de coordinación operativa de su sistema de refinación y de su comercio exterior.

No hay una explicación razonable y razonada de los objetivos que ha perseguido la diversificación del destino geográfico de las exportaciones de crudo pesado. Esta estrategia ha generado pérdidas importantes por lo que toca a los menores ingresos. En los últimos cuatro años, la estructura regional de los precios de exportación de PEMEx no sustentó la diversificación de mercados. La estrategia instrumentada careció de objetivos económicos y estratégicos precisos, así como de una lógica subyacente que la articulase. Además, el desempeño de las fórmulas que determinan los precios de exportación del crudo mexicano ha sido deficiente, pues adolecen de problemas estructurales que deben atenderse de inmediato.

Las exportaciones de crudo mexicano han sido desplazadas de Estados Unidos por crudos producidos principalmente en Norteamérica. El crudo pesado, por una mayor producción de crudo canadiense, y los ligeros, por el crecimiento de la producción de crudos extraligeros en Estados Unidos. La disponibilidad de crudos ligeros y extraligeros para la exportación ha disminuido tanto por una menor producción, como por el mayor volumen requerido de estos crudos para mezclar con crudos pesados y cumplir así con las especificaciones del Maya. A su vez, PEMEx deberá hacer un mayor uso de crudos ligeros en las refinerías que aún no se han reconfigurado, particularmente las que se encuentran tierra adentro, para reducir la producción excedente de combustóleo de alto azufre.

Resulta urgente revisar a fondo la estrategia de diversificación de mercados a la luz de una nueva estrategia de comercio 
exterior de hidrocarburos. La expansión de las exportaciones de Canadá al Golfo de México, después de 2020 y más adelante, constituye el principal reto competitivo para la exportación de crudo Maya. Con el propósito de recuperar participación de mercado en la costa estadounidense del Golfo, PMI tendría que desplegar un esfuerzo técnico de ventas en apoyo a la introducción de posibles cambios en sus fórmulas de precios y en la recalibración de las mismas.

En las actuales circunstancias, sería prudente hacer preparativos para una contingencia venezolana que limite temporalmente el flujo de crudo a mercados internacionales y a la costa del Golfo. Una mayor declinación del volumen de la producción y la interrupción potencial de las exportaciones de crudo venezolano pueden afectar el balance petrolero global y, de manera particular, el mercado de crudo pesado en la costa del Golfo.

La menor producción de crudo, la decreciente importancia económica de su exportación y el incremento sustancial de las importaciones de productos petrolíferos de mayor valor incrementarán en años venideros el déficit estructural de la balanza petrolera de México. La seguridad de suministro de productos petrolíferos y gas natural cobra mayor relevancia ante la creciente dependencia de importaciones provenientes de un solo país. Los riesgos que esto supone aconsejan desarrollar mecanismos que den mayor seguridad de suministro a las importaciones. Entre ellos, tendría que explorarse la posible vinculación contractual de las exportaciones de crudo y la importación de productos petrolíferos.

Pemex deberá liberar a PMI de responsabilidades que le son ajenas y que no se refieren directamente al comercio exterior de hidrocarburos. Tendrá que definir con mayor claridad y más explícitamente el ámbito de su quehacer institucional. PMi necesita alentar activamente una mayor transparencia de las transacciones en las que participa, obligándose a publicar periódica y oportunamente estadísticas detalladas de las mismas. Esta transparencia es esencial para la construcción de mercados competitivos. 


\section{REFERENCIAS BIBLIOGRÁFICAS}

Boué, Juan Carlos, con la colaboración de Liliana FigueroA, The Market for Heavy Sour Crude Oil in the US Gulf Coast. The Pemex/ Pdvsa Duopoly, Oxford, Institute for Energy Studies, 2002.

Franco Hernández, Gaspar, "Opportunities in Mexican Mature Fields", OE Digital, 1 de diciembre de 2017, en https://www. oedigital.com/drilling/rigs/item/16850-opportunities-inmexican-mature-fields

Gallagher, Kevin y Margaret Mrers, "China-Latin America Finance Database”, Washington, D. C., Inter-American Dialogue, 2016, en https:/ / www.thedialogue.org/map_list/

HaLfF, Antoine, "Slow Streaming to 2020: Innovation and Inertia in Marine Transport and Fuels", Center on Global Energy Policy, Columbia University, 10 de agosto de 2017, en https:// energypolicy.columbia.edu/sites/default/files/energy/ SlowSteamingto2020InnovationandInertiainMarineTransportandFuels817.pdf

Kalt, Amy, "It Ain't Heavy It's My Maya - Impact of Changes to the Mexican Heavy Crude Benchmark", RBN Energy, 11 de enero de 2017, en https://rbnenergy.com/it-aint-heavy-its-my-mayaimpact-of-changes-to-the-mexican-heavy-crude-benchmark

Kalt, Amy, "It Ain't Heavy It's My Maya - Impact of Changes to the Mexican Heavy Crude Benchmark - Part 2", RBN Energy, 26 de enero de 2017, en https:/ / rbnenergy.com/it-aint-heavy-its-mymaya-impact-of-changes-to-the-mexican-heavy-crude-benchmark-part-2

Lajous, Adrián, "Crude Oil Pricing Formulas. A Personal Commentary", Oxford Energy Forum, noviembre de 2006, en https:/ / www.oxfordenergy.org/wpcms/wp-content/uploads/2011/ 02/OEF-67.pdf

Lajous, Adrián, "US Crude Oil Exchanges with Mexico", Center on Global Energy Policy, Columbia University, febrero de 2015, en https:/ / energypolicy.columbia.edu/publications/report/us-crude-oil-exchanges-mexico

Lajous, Adrián, "Mexico's Hydrocarbon Dependence", Oxford Energy Forum, junio de 2017, en https://www.oxfordenergy.org/ 
publications/"New Fuel Oil Spec Adds Uncertainty to Maya Price", Argus, en https://www.argusmedia.com/pages/NewsBody. aspx?id $=1369682 \&$ menu=yes

U.S. Energy Information Administration, "Changing Quality Mix is Affecting Crude Oil Price Differentials and Refining Decisions", 21 de septiembre de 2017, en https://www.eia.gov/todayinenergy/detail.php?id=33012

WAlker, Mark A. y Richard J. CoOper, "Venezuela's Restructuring: A Realistic Framework", septiembre de 2017, en https://www. millsteibandco.com/news

\section{Informes}

Canadian Association of Petroleum Producers, "Crude Oil Forecast, Markets, \& Transportation”, 2017, en https://www.capp. $\mathrm{ca} /$ publications-and-statistics/publications/303440

Hernández, Gustavo, "Ayín-Batsil", en PeMeX Farmout Day, Houston, julio de 2017, en https://www.pemex.com/Documents/2 017pemexfarmoutday/5a.Gustavo Hernández - Offshore Farmout - Ayín Batsil.pdf

International Energy Agency, World Energy Outlook, París, OECD/ IEA, 2008.

OPEC $=$ Organization of the Petroleum Exporting Countries, "Monthly Oil Market Report", octubre de 2018, en https:// www.opec.org/opec_web/en/publications/338.htm

Petróleos Mexicanos, "Plan de Negocios de Pemex, 2017-2021", en https://www.pemex.com/acerca/plan-de-negocios/Documents/plannegocios-pmx_2017-2021.pdf

"The US Gulf Coast High Sulfur Fuel Oil Price: Oil Price Assessments", SEFP Global Platts, en https://www.platts.com/price-assessments/oil/usgc-fuel-oil

U.S. Energy Information Administration, Annual Energy Outlook, 2017, en https://www.eia.gov/outlooks/aeo/pdf/0383\%2820 $17 \% 29 . p d f$ 
U.S. Energy Information Administration, "Short-Term Energy Outlook", octubre de 2018, en https://www.eia.gov/outlooks/ steo/

U.S. Securities and Exchange Commission, "Petróleos Mexicanos, Form 6-K Report”, julio de 2017, en https:/ /www.pemex.com/ ri/reguladores/Informacion SEC/20170711_6K_2.pdf

U.S. Securities and Exchange Commission, "Petróleos Mexicanos, Annual Report (20F)”, 2016 y 2017, en https://www.pemex. $\mathrm{com} / \mathrm{ri} /$ reguladores/Paginas/informacion_sec.aspx

"Wcs Houston: A New Price Signal for Heavy Crude at US Gulf Coast", Argus White Paper, 2016, en https://www.argusmedia. $\mathrm{com} / \sim /$ media/files/pdfs/white-paper/argus-wcs-houstonwp.pdf?la=en

\section{Estadísticas}

Baytex Energy Corporation, "Historical wcs Pricing", octubre de 2018, en https:/ /www.baytexenergy.com/files/pdf/Operations /Historical_WCS_Pricing_October_2018.pdf

BP, Statistical Review of World Energy, junio de 2018, en https://www. bp.com/content/dam/bp/en/corporate/pdf/energy-economics/statistical-review/bp-stats-review-2018-full-report.pdf

$\mathrm{CNH}=$ Comisión Nacional de Hidrocarburos, "Reservas por asignación”, 2017, en https://portal.cnih.cnh.gob.mx/estadisticas. php

$\mathrm{CNH}=$ Comisión Nacional de Hidrocarburos, "Reservas por asignación”, 2018, en http://portal.cnih.cnh.gob.mx/estadisticas. php

CNH = Comisión Nacional de Hidrocarburos, "Reservas de hidrocarburos", en https://portal.cnih.cnh.gob.mx/estadisticas. php

CoREs, "España: importaciones de crudo por áreas geográficas y países, 1996-2017”, en https:/ / www.cores.es/es/estadisticas_

EIA = Energy Information Administration, "Crude Imports", en https://www.eia.gov/petroleum/imports/browser/-/?d=20\& $\mathrm{g}=3 \& \mathrm{vs}=$ PET_IMPORTS.WORLD-RP_3-3.A 
EIA = Energy Information Administration, "Crude Oil Production”, en https://www.eia.gov/dnav/pet/pet_crd_crpdn_adc_ mbbl_m.htm

EIA = Energy Information Administration, "Heavy Crude Imports", PADD3, en https://www.eia.gov/petroleum/imports/browser /-/?d=05egkc9du2000v00b044780o800tlpkmr7e7b72dukd409 $116 \mathrm{dc} 5 \& \mathrm{dt}=\mathrm{RF} \& \mathrm{~g}=3 \& \mathrm{co}=000000004000000 \& \mathrm{vs}=$ PET_IMPORTS.CTY_MX-RF_454-3.A

EIA = Energy Information Administration, "Landed Costs of Imported Crude for Selected Crude Streams”, en https://www. eia.gov/dnav/pet/pet_move_land2_k_m.htm

EIA $=$ Energy Information Administration, "Percentage of Total Imported Crude Oil by API Gravity and Downstream Charge Capacity of Operable Petroleum Refineries”, en https://www. eia.gov/dnav/pet/pet_move_ipct_k_m.htm

EIA = Energy Information Administration, "Petroleum and Other Liquids, Spot Prices", en https://www.eia.gov/petroleum/ data.php

EIA = Energy Information Administration, "U.S. Imports by Country of Origin, and Exports by Destination", en https://www. eia.gov/petroleum/data.php

Norwegian Ministry of Petroleum and Energy, "Production", en https://www.norskpetroleum.no/en/facts/production/

Pemex, "Base de Datos Institucional", en https://www.ebdi.pemex.com

PMI = Petróleos Mexicanos Internacional, "Fórmulas de los Crudos Mexicanos de Exportación”, en https://www.pmi.com.mx/ Documents/FormulasCrudos.pdf

SENER = Secretaría de Energía, "Rondas petroleras consolidan a México como uno de los destinos de inversión más atractivos del mundo", Boletín de prensa 041, 23 de mayo de 2017, en https://www.gob.mx/sener/prensa

SENER = Secretaría de Energía, "Sistema de Información Energética”, en https:/ / sie.energia.gob.mx/bdiController.do?action $=$ temas 
UK Government, "Crude Oil and Petroleum: Production, Imports and Exports, 1890 to 2017", en https://www.gov.uk/government/statistical-data-sets / crude-oil-and-petroleum-production-imports-and-exports-1890-to-2011 
